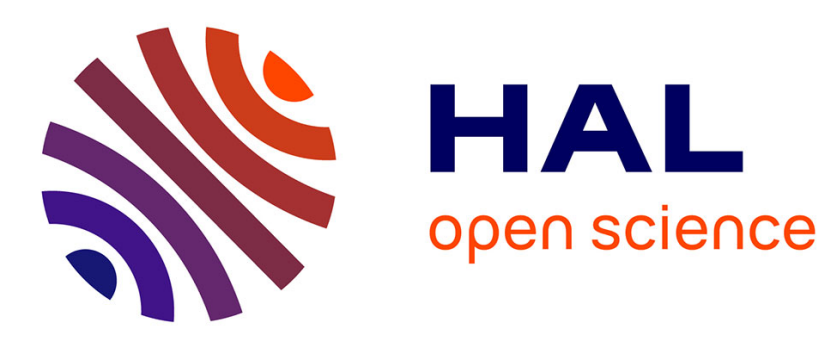

\title{
Untargeted Metabolomics Reveal Lipid Alterations upon 2-Deoxyglucose Treatment in Human HaCaT Keratinocytes
}

\author{
Pierre Le Pogam, Mickael Doué, Yann Le Page, Denis Habauzit, Maxim \\ Zhadobov, Ronan Sauleau, Yves Le Dréan, David Rondeau
}

\section{To cite this version:}

Pierre Le Pogam, Mickael Doué, Yann Le Page, Denis Habauzit, Maxim Zhadobov, et al.. Untargeted Metabolomics Reveal Lipid Alterations upon 2-Deoxyglucose Treatment in Human HaCaT Keratinocytes. Journal of Proteome Research, 2018, 17 (3), pp.1146-1157. 10.1021/acs.jproteome.7b00805 . hal-01730281

\section{HAL Id: hal-01730281}

\section{https://hal-univ-rennes1.archives-ouvertes.fr/hal-01730281}

Submitted on 6 Jul 2018

HAL is a multi-disciplinary open access archive for the deposit and dissemination of scientific research documents, whether they are published or not. The documents may come from teaching and research institutions in France or abroad, or from public or private research centers.
L'archive ouverte pluridisciplinaire HAL, est destinée au dépôt et à la diffusion de documents scientifiques de niveau recherche, publiés ou non, émanant des établissements d'enseignement et de recherche français ou étrangers, des laboratoires publics ou privés. 


\section{Untargeted metabolomics reveal lipid alterations upon 2-deoxyglucose treatment in human HaCaT keratinocytes}

Pierre Le Pogam ${ }^{1}$, Mickael Doué ${ }^{1}$, Yann Le Page ${ }^{2}$, Denis Habauzit ${ }^{2}$, Maxim Zhadobov ${ }^{1}$, Ronan Sauleau ${ }^{1}$, Yves Le Dréan ${ }^{2}$ and David Rondeau ${ }^{1,3^{*}}$

1 Institute of Electronics and Telecommunications of Rennes (IETR), UMR CNRS 6164, University of Rennes 1, Campus de Beaulieu, 263 avenue du Général Leclerc, 35042 Rennes Cedex, France.

2 Transcription, Environment and Cancer Group, Institute for Research on Environmental and Occupational Health (IRSET), Inserm UMR1085, University of Rennes 1, 9 avenue du Prof. Léon Bernard, 35043 Rennes Cedex, France.

${ }^{3}$ Département de Chimie, Université de Bretagne Occidentale, 6 avenue Victor Le Gorgeu, 29238 Brest, Cedex, France.

*Corresponding author:

David Rondeau, Institute of Electronics and Telecommunications of Rennes (IETR), UMR CNRS 6164, University of Rennes 1, Campus de Beaulieu, 263 avenue du Général Leclerc, 35042 Rennes Cedex, France.

tel: +332 23235445, email: david.rondeau@univ-rennes1.fr 


\begin{abstract}
The glucose-analogue 2-deoxyglucose (2-DG) impedes cancer progression in animal models and is currently being assessed as an anti-cancer therapy. Yet, the mode of action of this drug of high clinical significance has not been fully delineated. In an attempt to better characterize its pharmacodynamics, an integrative UPLC-Q-Exactive based joint metabolomic and lipidomic approach was undertaken to evaluate the metabolic perturbations induced by this drug in human $\mathrm{HaCaT}$ keratinocyte cells. R-XCMS data processing and subsequent multivariate pattern recognition, metabolites identification and pathway analyses identified 8 metabolites that were most significantly changed upon a 3 h 2-DG exposure. Most of these dysregulated features were emphasized in the course of lipidomic profiling and could be identified as ceramide and glucosylceramide derivatives, consistently with their involvement in cell death programming. Even though metabolomic analyses did not generally afford such clear-cut dysregulations, some alterations in phosphatidylcholine and phosphatidylethanolamine derivatives could be highlighted as well. Overall, these results support the adequacy of the proposed analytical workflow and might contribute to a better understanding of the mechanisms underlying the promising effects of 2-DG.
\end{abstract}

Keywords: Metabolomics, Lipidomics, 2-DG, UHPLC-MS, Ceramides, Glycosylceramides, Galactosylglycerol 


\section{INTRODUCTION}

An increase of aerobic glycolysis, also known as the Warburg effect, ${ }^{1}$ is a current hallmark of cancer, leading malignant cells to have a higher glucose consumption than normal cells. As a consequence, those cells are more vulnerable to glucose deprivation. ${ }^{2}$ Thus, when challenged with glycolytic inhibitors, ATP synthesis is shut off and the cell succumbs to this treatment. Accordingly, glycolytic inhibitors are increasingly regarded as a new class of anticancer agents, likely to display broad therapeutic applications. ${ }^{3-5}$ Among them, 2-deoxyglucose (2-DG), a nonmetabolizable glucose analogue, was shown to strongly inhibit cancer cell proliferation and is a promising therapeutic strategy to kill cancer cells and overcome multidrug resistance. ${ }^{6}$ Several studies supported the subsequent assessment of 2-DG in clinical trials. Some such examples include the evaluation of 2-DG in patients having castrate-resistant prostate cancer, ${ }^{7}$ glioblastoma multiforme ${ }^{8}$ cerebral gliomas ${ }^{9}$ and various advanced solid tumors. ${ }^{10}$ However, the molecular mechanisms underlying the effects of $2-\mathrm{DG}$ still remain controversial. ${ }^{11,12}$ The addition of 2-DG to cells results in a glucose starvation-like response, even when cells are in a glucose-rich environment. ${ }^{13,14}$ It was also demonstrated that 2-DG can be uptaken and converted into 2-DG6P with the absence of a hydroxyl group on $\mathrm{C}_{2}$ precluding its subsequent catabolism by phosphoglucose isomerase, which results in its accumulation. ${ }^{15,16}$ This accumulation might then trigger a product inhibition of hexokinase, the enzyme responsible for the rate-limiting step of glycolysis, thereby leading to a depletion of ATP. Besides, 2-DG was reported to inhibit the biosynthesis of cell wall glycoproteins and oligosaccharides, rendering the cells osmotically fragile. $^{17,18}$ Along with these pharmacodynamics, 2-DG also inhibits N-linked protein glycosylation, competing with mannose for addition onto $\mathrm{N}$-acetylglucosamine residues. ${ }^{19}$ This generates misfolded proteins which might in turn lead to endoplasmic reticulum (ER) stress. Such stress is regarded as the main mechanism by which 2-DG induces autophagy ${ }^{20,21}$ and apoptosis. $^{22}$ Recently, a joint microarray-based and RT-PCR approach revealed that 2-DG strongly modified the transcriptome of human primary culture of keratinocyte, with the expression of 632 coding genes being modified. ${ }^{23}$ The use of in vitro cell models offers advantages over other subject or animal models, which include easier experimental variables, greater reproducibility, lower cost and thus easily interpretable results. ${ }^{24}$ Indeed, metabolic profiles acquired from whole organisms are strongly affected by various parameters such as gender, age ${ }^{25}$ daily habits (diet, tobacco, ${ }^{26}$ coffee consumption ${ }^{27} \ldots$ ) that might exert significant influences on biofluids composition. 
To the best of our knowledge, no metabolomic approaches were dedicated to unraveling the promising cytotoxicity of 2-DG. Metabolomics, i.e the global assessment of metabolites in a biological sample, represent the 'sharp end' of systems biology, encompassing the up-stream interactions between the genome, transcriptome, and proteome. ${ }^{28}$ Metabolomic strategies were implemented to a variety of human studies and pinpointed several biomarkers of various diseases either to be applied to early diagnosis or to monitor responses to treatments. ${ }^{29-32}$ Metabolomes are extremely complex systems owing to the highly different physicochemical properties of metabolites. As unbiased approaches, metabolomic studies should not exclude metabolite classes and might rely on analytical techniques possessing high selectivity and sensitivity. ${ }^{33}$ In order to separate the hydro soluble fraction and the hydrophobic phase, different extraction procedures can be assessed. Lipids of all major classes are known to be recovered via chloroform/methanol extraction systems. ${ }^{34-36}$ With the introduction of the liquid-liquid Methyl tert-Butyl Ether (MTBE) extractions in lipidomics, ${ }^{37}$ one can consider that the use of such systems can provide similar or better recovery rates of all major classes of lipids while ensuring faster and cleaner recoveries compared to previous benchmark methods. ${ }^{38}$ Consequently, in our work, prior to undertaking large scale metabolomic studies, different extraction schemes were compared differing by the nature of both the quenching and organic solvents (either $\mathrm{MeOH}$ or $\mathrm{MeOH} / \mathrm{H}_{2} \mathrm{O}$ $(4 / 1, v / v)$ and MTBE or $\mathrm{CHCl}_{3}$, respectively). Untargeted LC-HRMS based strategies were also used since they represent the prevalent strategy to detect a wide range of chemical classes and thereby grant as broad a picture of metabolism as achievable. ${ }^{39}$ As for related omics, metabolomic workflow generates thousands of data points among which only a tiny proportion might hold meaningful elements with mechanistic or explanatory power, so that relevant chemometric and statistical tools are mandatory to handle such large data sets. ${ }^{40}$

In an attempt to assess the metabolic alterations triggered upon exposure to 2-DG, a UHPLCHRMS based untargeted metabolomic approach was designed. The main aim of this investigation was to delineate the molecular mechanisms underlying the effects of 2-DG on human $\mathrm{HaCaT}$ keratinocytes, as we previously reported on transcriptomic alterations occurring upon 2-DG exposure on this cell line. ${ }^{23}$ To get the widest possible insight, lipidomic and metabolomic analyses of extracellular and endocellular extracts were undertaken, both in positive and negative-ion modes. Subsequently, R-XCMS data processing, multivariate pattern recognition, metabolites identification and pathway analyses were delineated in the presence and absence of treatment by this drug. To the best of our knowledge, this study represents the first metabolomic investigation dedicated at studying the effects of 2-DG. 


\section{EXPERIMENTAL SECTION}

Chemicals, reagents and materials. LC-MS grade water, methanol $(\mathrm{MeOH})$, methyl tert-butyl ether (MTBE), chloroform $\left(\mathrm{CHCl}_{3}\right)$, acetonitrile $(\mathrm{MeCN})$, 2-propanol (IPA), ammonium acetate, acetic acid and 2-Deoxy-D-glucose (2-DG) were purchased from SigmaAldrich (St. Louis, MO, USA). Phosphate-buffered saline-based cell disruption buffer was purchased from Gibco (Life Technologies, Zug, Switzerland).

The standard mixtures used for the external calibration of the MS instrument (Calmix-positive, for the positive ionization mode, consisting of caffeine, L-methionyl-arginyl-phenylalanylalanine acetate and Ultramark 1621, and Calmix-negative, for the negative ionization mode, consisting of acetic acid, sodium dodecyl sulfate, taurocholic acid sodium salt hydrate, Ultramark 1621) were obtained from Thermo Fisher Scientific (Waltham, MA, USA).

1,2-dipentadecanoyl-sn-glycero-3-phosphocholine (PC(15:0/15:0)), 1-pentadecanoyl-2-hydroxysn-glycero-3-phosphocholine (Lyso PC(15:0)), 1,2-diheptadecanoyl-sn-glycero-3phosphoethanolamine $\quad(\mathrm{PE}(17: 0 / 17: 0))$ and N-heptadecanoyl-D-erythro-sphingosine (Cer(d18:1/17:0)) were purchased from Coger (Paris, France), ${ }_{L}$-tryptophan-2,3,3-d $\mathrm{d}_{3}\left(\right.$ Trypto- $\left._{3}\right)$, indole-2,4,5,6,7- $\mathrm{d}_{5}$-3-acetic acid (Ind-AA- $\mathrm{d}_{5}$ ), 1,14-tetradecanedioic- $\mathrm{d}_{24}$ acid (Tetra-A- $\left.\mathrm{d}_{24}\right)$ from C.I.L (Cluzeau Info Labo, Sainte-Foy-La-Grande, France), and 1,2,3-triheptadecanoyl-glycerol (TG (17:0)), pentadecanoic acid (C15:0), tricosanoic acid (C23:0), heptadecanoic acid (C17:0),

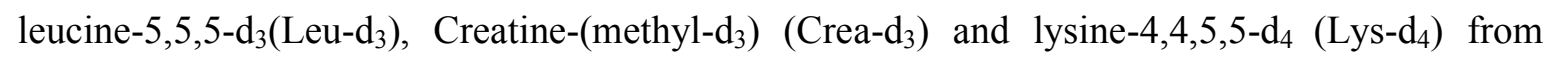
Sigma-Aldrich. Stock standard solutions ( $1 \mathrm{mg} / \mathrm{L}$ ) were prepared in $\mathrm{CHCl}_{3}$ (for lipid compounds) or in $\mathrm{MeOH}$ and stored at $-20^{\circ} \mathrm{C}$.

Internal standard (IS) solution containing C17:0, Crea- $\mathrm{d}_{3}$ and $\mathrm{Lys}^{-\mathrm{d}_{4}}$ at $10 \mathrm{ng} / \mu \mathrm{L}$, lipidomic external standard (ES) solution containing (PC (15:0/15:0), Lyso PC (15:0), PE (17:0/17:0), TG (17:0), Cer (d18:1/17:0), C15:0 and C23:0 at 0.5 ng/ $\mu \mathrm{L}$ and metabolomic ES solution containing Leu- $\mathrm{d}_{3}$, Trypto- $\mathrm{d}_{3}$, Ind-AA- $\mathrm{d}_{5}$ and Tetra-A- $\mathrm{d}_{24}$ at $1 \mathrm{ng} / \mu \mathrm{L}$ were subsequently prepared in $\mathrm{CHCl}_{3}$ (lipidomic ES) or in $\mathrm{MeOH}$ (metabolomic ES).

Cell culture. Human keratinocyte cell line (HaCaT) was cultured as previously described. $^{41}$ To exclude any problem of senescence or drift of the cellular population, the experiments on keratinocytes were conducted at earlier passages (between 4 and 10). A strict control of cell growth for subsequent normalization of metabolic profiles according to cell number is mandatory to enable cross-sample comparisons. Protein assessment was here chosen as an indicator of cell amount. ${ }^{42}$ For metabolomic studies, cells (seeded at a density of 60000 cells $/ \mathrm{cm}^{2}$ ) were transferred to six-well plates for 2 days. Then, cells were either directly processed or treated with 2-DG dissolved in water to reach a final concentration of $20 \mathrm{mmol} / \mathrm{L}$, 
for $3 \mathrm{~h}^{23}$, before quenching and metabolites extraction. This treatment was previously shown to induce a deep modification of gene expression. ${ }^{23}$ To control 2-DG efficiency, the total amount of ATP was evaluated from wells treated in the same conditions using an ATP Bioluminescence Assay kit (Roche, Indianapolis, IN, USA). For normalization, total protein concentration was assessed in parallel using a Bio-Rad DC protein assay kit (Hercules, CA, USA), and total amount of ERK protein was evaluated by western blotting using anti-ERK1 (K-23) antibody (Santa Cruz Biotechnology, Dallas, Texas, USA). ${ }^{43}$ Real Time PCR analyses on ER-chaperons, BIP and ORP150, were performed as previously described. ${ }^{41}$ Analyses were performed in triplicate and Welch's two-sample $t$-test was used to compute $\mathrm{p}$ values between control and treated groups.

Quenching and Cell Recovery. Cell metabolism must be deactivated through the quenching of biochemical processes that might alter the metabolic profiles and yield misleading results. ${ }^{44}$ Even though the trypsination and cell scraping in a buffer solution are considered as the main possible approaches to harvest adherently growing cells for metabolomic studies, ${ }^{37}$ the trypsination treatment step is reported to damage cell membranes with possible metabolite leakages, ${ }^{45}$ and can be thereby regarded as inadequate for metabolomics. ${ }^{37}$ Six-well plates were thus taken out of the $37^{\circ} \mathrm{C}$ incubator and immediately placed on ice during the whole workflow described below.

Extraction procedures and Sample Preparations. The overall metabolome comprises the endo-metabolome (i.e metabolites present in the cells) and the exo-metabolome (i.e metabolites encountered in the extracellular medium). As metabolites are continuously exchanged between intra- and extracellular environments (owing to uptake of nutrients, excretion of metabolites...), these fluxes can be monitored in the spent medium composition. ${ }^{46}$ In an attempt to deepen the coverage of metabolites, the performances of several extraction solvent systems were evaluated: (i) $\mathrm{MeOH} / \mathrm{H}_{2} \mathrm{O}(4 / 1, v / v)$ and $\mathrm{MTBE}$, (ii) $\mathrm{MeOH}$ and MTBE and (iii) $\mathrm{MeOH} / \mathrm{H}_{2} \mathrm{O}(4 / 1, v / v)$ and $\mathrm{CHCl}_{3}$. As the first set of solvents afforded the best results (see in Results and Discussion section), the protocol described below is established with this specific system.

Exo-cellular fractions. $100 \mu \mathrm{L}$ of the growth medium in each plate were collected into an eppendorf and the rest was discarded by aspiration. To the $100 \mu \mathrm{L}$ collected medium, $400 \mu \mathrm{L}$ of IS solution $(1 \mathrm{ng} / \mu \mathrm{L})$ in $\mathrm{MeOH} / \mathrm{H}_{2} \mathrm{O}(4 / 1, \mathrm{v} / \mathrm{v})$ were added. The extract was further vortexed (10 sec, 3 times, spaced by 1 minute break in ice) prior to adding $550 \mu \mathrm{L}$ of MTBE. Then, 200 $\mu \mathrm{L}$ of cold-water were added and the same vortexing procedure was repeated. The solution was 
further centrifuged at $12,000 \mathrm{~g}$ and $4{ }^{\circ} \mathrm{C}$ for $15 \mathrm{~min} .300 \mu \mathrm{L}$ of the upper lipidic phase were transferred to a vial and $40 \mu \mathrm{L}$ of the lipidomic ES solution $\left(0.5 \mathrm{ng} / \mu \mathrm{L}\right.$ in $\left.\mathrm{CHCl}_{3}\right)$ were added before evaporation to dryness under $\mathrm{N}_{2}$ followed by reconstitution with $200 \mu \mathrm{L}$ of $\mathrm{MeCN} / \mathrm{IPA} / \mathrm{H}_{2} \mathrm{O}(65: 30: 5, \mathrm{v} / \mathrm{v} / \mathrm{v})$ solution. For the lower hydrophilic phase (metabolomic fraction), $300 \mu \mathrm{L}$ were centrifugally filtered through a Millipore $10 \mathrm{KDa}$ cutoff filter to remove proteins (12 $000 \mathrm{~g}, 4^{\circ} \mathrm{C}, 20 \mathrm{~min}$.). $40 \mu \mathrm{L}$ of the metabolomic ES solution $(1 \mathrm{ng} / \mu \mathrm{L}$ in $\mathrm{MeOH})$ were added to the filtrated solution prior to evaporating it to dryness under $\mathrm{N}_{2}$. The dry extract was subsequently reconstituted in $200 \mu \mathrm{L}$ of $\mathrm{MeCN}_{2} \mathrm{H}_{2} \mathrm{O}(90: 10, \mathrm{v} / \mathrm{v})$ solution. Quality control samples (QC) were prepared by mixing $20 \mu \mathrm{L}$ aliquots of each sample. The samples were stored at $-80^{\circ} \mathrm{C}$ prior to UHPLC/MS analysis. 
Endo-cellular fractions. After growth medium aspiration, the cells were washed with 1 $\mathrm{mL}$ of cold phosphate buffered saline solution. Cell detachment was performed by scraping cells with $1250 \mu \mathrm{L}$ of PBS solution. A $250 \mu \mathrm{L}$-aliquot was recovered for subsequent dosing of the total protein content. To the remaining $1000 \mu \mathrm{L}$ were added $400 \mu \mathrm{L}$ of IS solution $(1 \mathrm{ng} / \mu \mathrm{L})$ dissolved in $\mathrm{MeOH} / \mathrm{H}_{2} \mathrm{O}(4 / 1, \mathrm{v} / \mathrm{v})$. In order to facilitate cell disruption and metabolite extraction, the cells were frozen at $-80^{\circ} \mathrm{C}$ for $20 \mathrm{~min}$. This solution was further added with 550 $\mu \mathrm{L}$ of MTBE and vortexed three times for 10 seconds (with one minute breaks in ice). To ensure liquid-liquid extraction, $200 \mu \mathrm{L}$ of water were then added and the same vortexing sequence was applied. The solution was then centrifuged at $12000 \mathrm{~g}$ and $4{ }^{\circ} \mathrm{C}$ for $15 \mathrm{~min} .300 \mu \mathrm{L}$ of the upper lipidic phase were transferred to a vial and $40 \mu \mathrm{L}$ of the lipidomic ES solution $(0.5 \mathrm{ng} / \mu \mathrm{L}$ in $\mathrm{CHCl}_{3}$ ) were added before evaporation to dryness under $\mathrm{N}_{2}$ followed by reconstitution with 200 $\mu \mathrm{L}$ of $\mathrm{MeCN} / \mathrm{IPA} / \mathrm{H}_{2} \mathrm{O}(65: 30: 5, \mathrm{v} / \mathrm{v} / \mathrm{v})$ solution. For the lower hydrophilic phase (metabolomic fraction), $300 \mu \mathrm{L}$ were centrifugally filtered through a Millipore $10 \mathrm{KDa}$ cutoff filter to remove proteins $\left(12000 \mathrm{~g}, 4^{\circ} \mathrm{C}, 20 \mathrm{~min}\right) .40 \mu \mathrm{L}$ of the metabolomic ES solution $(1 \mathrm{ng} / \mu \mathrm{L}$ in $\mathrm{MeOH})$ were added to the filtrated solution prior to evaporating it to dryness under $\mathrm{N}_{2}$. The dry extract was subsequently reconstituted in $200 \mu \mathrm{L}$ of $\mathrm{MeCN} / \mathrm{H}_{2} \mathrm{O}(90: 10$, v/v) solution. Quality control samples (QC) were prepared by pooling $20 \mu \mathrm{L}$ aliquots of all studied samples. The samples were stored at $-80^{\circ} \mathrm{C}$ while pending UHPLC/MS analysis.

An overview of this pipeline is provided in Figure 1.

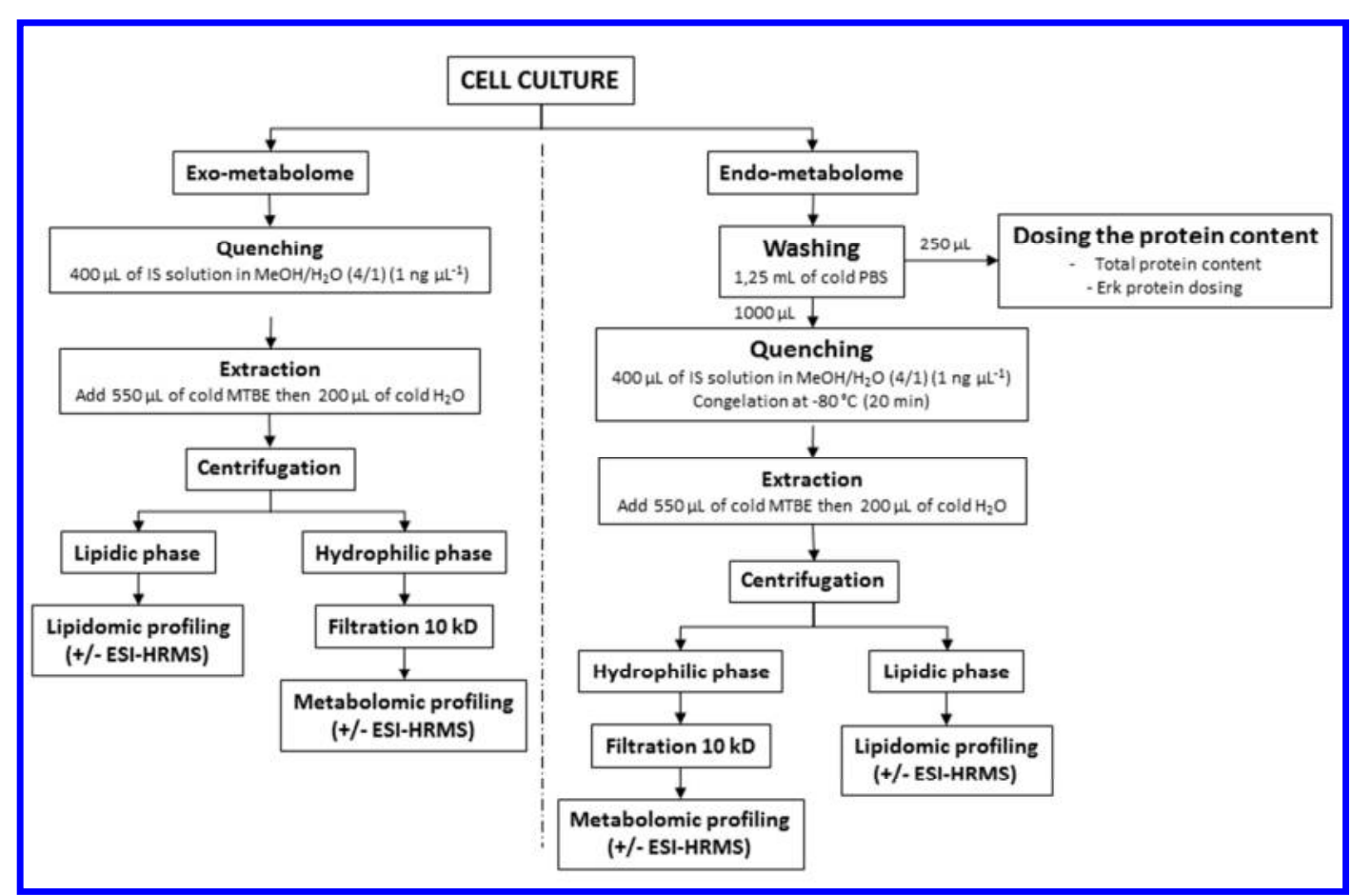


Figure 1. Schematic workflow of the analytical process for sample preparation.

Liquid chromatography-high resolution mass spectrometry. Metabolomic analyses were performed in a Waters Acquity UPLC chromatogram coupled online to a Thermo QExactive mass spectrometer. Organic phases were analyzed by the lipidomic-RPLC HRESI-MS approach. Polar fractions were processed following a HILIC HRESI-MS strategy for metabolic profiling purposes. In both cases, the sample injection volume was $5 \mu \mathrm{L}$ and the flow rate was set at $300 \mu \mathrm{L} / \mathrm{min}$.

Lipidomic RPLC analyses. Reverse-phase LC separation was achieved in an Acquity $\mathrm{CSH} \mathrm{C}_{18}$ column $(1.7 \mu \mathrm{m}, 2.1 \quad \mathrm{x} \quad 100 \mu \mathrm{mm}$; Waters $)$ Eluent solutions were $\mathrm{MeCN} / \mathrm{H}_{2} \mathrm{O} /$ ammonium acetate $1 \mathrm{M} /$ acetic acid (600/390/10/1, v/v/v/v) (solvent A) and IPA/MeCN/ $\mathrm{H}_{2} \mathrm{O} /$ ammonium acetate $1 \mathrm{M} /$ acetic acid $(880 / 100 / 10 / 10 / 1, \mathrm{v} / \mathrm{v} / \mathrm{v} / \mathrm{v} / \mathrm{v})$ (solvent B). A 25 min gradient was performed as follows: the initial solvent system consisted of $60 \% \mathrm{~A}$ and $40 \% \mathrm{~B}$. For the two first minutes, the gradient was linearly changed to $50 \% \mathrm{~A}$ and $50 \% \mathrm{~B}$. Then, the proportion was increased to reach $70 \% \mathrm{~B}$ at 12 minutes. The final elution conditions (1\% A and $99 \% \mathrm{~B}$ ) were obtained at $17 \mathrm{~min}$ and held for 8 minutes. Afterwards, the initial conditions were recovered and maintained for 4 minutes for column conditioning. Samples were ionized in positive and negative-ion modes with ESI parameters as follows: sheath gas flow, 55 Arbitrary Units (AU); auxiliary gas flow, $10 \mathrm{AU}$; capillary temperature, $300^{\circ} \mathrm{C}$; spray voltage, $3.5 \mathrm{kV}$; $\mathrm{S}$ lens radiofrequency, 50 AU. HMRS data were acquired in full-scan mode over the $\mathrm{m} / \mathrm{z}$ range 150-1500 at a resolving power of 35000 Full Width Half Maximum (FWHM) at $m / z 200$. The Automatic Gain Control (AGC target) was set at high dynamic range $\left(5 \times 10^{5}\right)$ with a maximum injection time of $100 \mathrm{~ms}$.

Metabolomic HILIC analyses. HILIC chromatography was performed in a SeQuant ZICHILIC column $\left(3.5 \mu \mathrm{m}, 2.1 \times 100 \mathrm{~mm}\right.$, Merck). The mobile phase consisted of $\mathrm{H}_{2} \mathrm{O}$ /ammonium acetate/acetic acid (980/10/1, v/v/v) (solvent A, adjusted at $\mathrm{pH} 4.75)$ and of $\mathrm{MeCN} /$ solvent $\mathrm{A}$ (950/50) (solvent B). The elution sequence lasted $16 \mathrm{~min}$ and was programmed as follows: the initial conditions $(5 \%$ A; $95 \%$ B) were maintained for two minutes prior to being linearly modified to $20 \% \mathrm{~A}$ and $80 \% \mathrm{~B}$ at $5 \mathrm{~min}$. The proportion of phase A was linearly increased to reach $40 \%$ at $12 \mathrm{~min}$. The final plateau (60\% A and 40\% B) was obtained at 14 min and held for $2 \mathrm{~min}$. To condition the column, the initial conditions were then recovered for $10 \mathrm{~min}$. Samples were ionized in positive and negative-ion modes with ESI parameters as follows: sheath gas flow, $55 \mathrm{AU}$; auxiliary gas flow, $10 \mathrm{AU}$; capillary temperature, $300^{\circ} \mathrm{C}$; spray voltage, $3.0 \mathrm{kV}$; $\mathrm{S}$ - 
lens radiofrequency, 50 AU. HRMS data were acquired in full-scan mode over the $m / z$ range 65 975 at a resolving power of $35000 \mathrm{FWHM}$ at $\mathrm{m} / \mathrm{z}$ 200. The Automatic Gain Control (AGC target) was set at high dynamic range $\left(5 \times 10^{5}\right)$ with a maximum injection time of $100 \mathrm{~ms}$.

Quality control. Each sample was analyzed 6 times in a randomized batch sequence. Prior to each batch analysis, the mobile phase was run for $1.5 \mathrm{~h}$, followed by six QC samples to enable proper column equilibration and conditioning. To monitor and overcome analytical drifts in UPLC-MS, quality control samples were injected at regular intervals during the experimental sequence (i.e every 8 samples), in line with published guidelines. ${ }^{47}$ For each analysis, the ions that were detected during either the dead volume $(<0.6 \mathrm{~min})$ or the conditioning of the column (>26 min) were eliminated. Features were considered reproducible if their Coefficient of Variation (CV) among QC samples were below 30\%, as suggested elsewhere. ${ }^{48,49}$ Adversely, features that did not respect this condition were removed from the data subset. To further assess the validity of the analytical strategy described herein and assist in retention time correction, external isotope-labeled metabolites were added after the extraction process as detailed earlier. These standard metabolites were selected to encompass a wide range of polarities and chemical structures. Thus, their retention times span across the whole chromatogram. Internal standards (i.e endogenous metabolites added prior to sample extraction) were also included to track sample extraction efficiency.

Data processing. Raw data were processed using R-XCMS to help with the putative identification of potential biomarkers of exposure to 2-DG. XCMS workflow involves typical data processing steps including peak discrimination, peak filtering and peak alignment. This workflow generates a data matrix presented as a feature list comprising their integrated intensities (Extracted Ion Chromatogram peak area) along with the corresponding Fold Change (FC) and associated ANOVA p-values. ${ }^{50}$ Final peak picking parameters were: prefilter $=(\mathrm{c}$, average chromatographic signal $/ 10)$, peak width $=\mathrm{c}(5,25), \operatorname{snthresh}=6, \operatorname{mzdiff}=0.01, \mathrm{ppm}=15$. Alignment $(\mathrm{bw}=9, \operatorname{minfrac}=0.66, \operatorname{minsamp}=4, \operatorname{mzwid}=0.008)$ and retention time correction (obiwarp, plottype $=\mathrm{c}($ deviation), profstep $=1)$. Regarding univariate analyses, the Coefficient of Variation $(\mathrm{CV})$ within $\mathrm{QC}$ samples was obtained by dividing the standard deviation by the mean intensity of each feature, and a histogram displaying the CV distribution was generated. Then, the computation of the Fold-Change ratio (FC, relating abundance between control and treated samples) along with the corresponding ANOVA p-value (statistical significance from a Student $t$-test) streamlined the selection of the features of interest. The frames of interest were selected according to the following criteria: $\mathrm{CV}$ QC $<30 \%, \mathrm{FC}>2$ and ANOVA p-value $<0.05$. At this 
stage, Extracted Ion Chromatograms were individually checked to retain as putative biomarkers the features for which no overlap occurred between control and 2-DG treated samples. Box and Whiskers plot related to all metabolites of potential interest were individually checked to retain the features for which limited to null overlap existed between control and treated values. Practically speaking, the features for which the $75^{\text {th }}$ percentile of the sample group displaying the lower value was below the $25^{\text {th }}$ percentile of the sample group having the higher value were selected as potential biomarkers of exposure. Horizontal lines appearing in the boxes illustrate the median, bottom and top boundaries of boxes refer to the lower and upper quartiles, at last whiskers depict the $5^{\text {th }}$ and $95^{\text {th }}$ percentiles. Multivariate analyses by Principal Component Analysis (PCA) were performed using Progenesis QI (v. 2.1) (Non-linear Dynamics, Newcastleupon-Tyne, UK).

Tentative identification of metabolites. The tentative identification of the metabolites of interest was carried out as follows. The exact masses of their monoisotopic molecular weight were tentatively identified against the Progenesis Metascope "Biomolecules" database, and the free online databases, including METLIN ${ }^{51,52}$ (http://metlin.scripps.edu) and HMDB $^{53,54}$ (http://www.hmdb.ca/). Metabolite hits were searched for with a tolerance of $\pm 5 \mathrm{ppm}$ for both these databases considering several possible monoisotopic masses for each feature of interest (protonated molecules, ion adducts...). For lipidomic sequences, LipidMaps online database ${ }^{55}$ (University of California, San Diego, CA - www.lipidmaps.org) was also consulted to elect the most suitable markers, considering a maximum adopted mass accuracy error of $\pm 5 \mathrm{ppm}$. 


\section{RESULTS AND DISCUSSION}

Assessing the cellular effects of 2-DG. First of all, ATP concentration and expression levels of the mRNA of two ER-resident chaperons, BIP (immunoglobulin heavy-chain binding protein, also named HSPA5) and ORP150 (oxygen regulated protein $150 \mathrm{kDa}$, or HYOU1), were measured, following experimental procedures which some of us previously described. ${ }^{56}$ The results depicted in Figure 2 reveal that 2-DG treatment of HaCaT keratinocyte cells leads to (i) a depletion in intracellular ATP (i.e 10-fold decrease of ATP concentration, Figure 2a, $\mathrm{P}=0.00283$, Welch two-sample $t$ test) and (ii) an increase of the expression of the ER-stress sensors BIP/ORP150 as the cell lines are exposed to 2-DG (see Figure $2 b)(P=0.00286 / 0.00292$, respectively, Welch two-sample $t$-test). These results are in agreement with the literature ${ }^{57,58}$ and underline the effectiveness of 2-DG treatment.

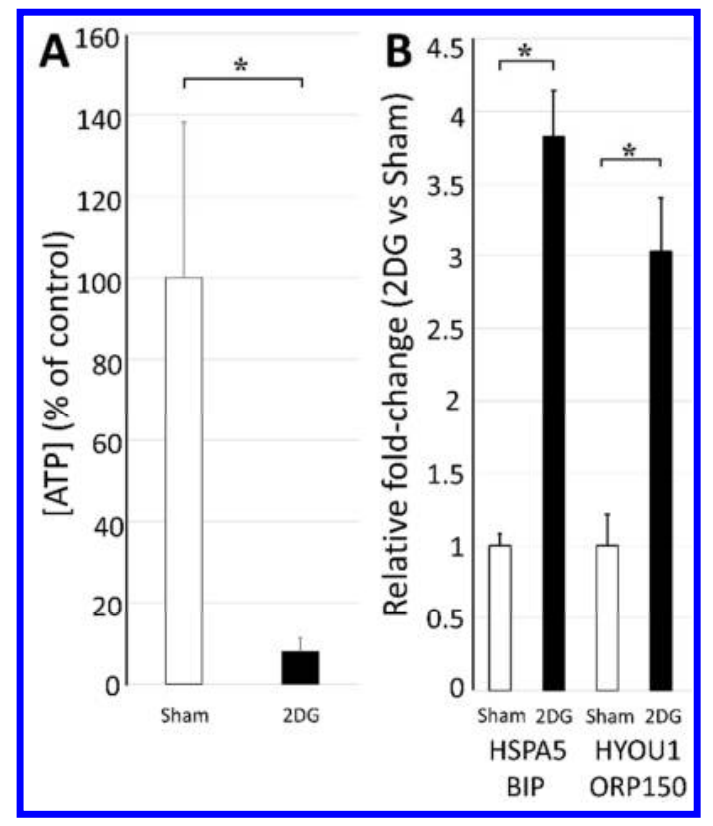

Figure 2. Comparison of intracellular ATP content (A) and mRNA levels of ER-resident chaperons involved in ER stress response (HSPA5/BIP and HYOU1/ORP150) (n=3) (B) upon 2-DG treatment. *P $<0.01$, Welch two-sample $t$ test.

Optimization of the extraction procedure. Three extraction procedures were compared using the following experimental setups (i) $\mathrm{MeOH} / \mathrm{H}_{2} \mathrm{O}(4 / 1, v / v)$ and $\mathrm{MTBE}$, (ii) $\mathrm{MeOH}$ and MTBE and (iii) $\mathrm{MeOH} / \mathrm{H}_{2} \mathrm{O}(4 / 1, v / v)$ and $\mathrm{CHCl}_{3}$. These sample processing methods were attempted on three different control samples that were subsequently submitted to the previously described metabolomic workflow (i.e each sample analyzed 6 times, in a randomized sequence). These different procedures were compared with respect to the number of detected features and proportions of ions with CV below 30\%, with the results being collated in Table S1. Regarding the number of detected features, all three approaches granted results that were consistent there 
between. Nevertheless, results obtained with the MeOH/MTBE approach revealed a reduced proportion of features having a $\mathrm{CV}$ QC $<30 \%$ in lipidomic sequences. The outcomes of the $\mathrm{MeOH} / \mathrm{H}_{2} \mathrm{O} / \mathrm{MTBE}$ and $\mathrm{MeOH} / \mathrm{H}_{2} \mathrm{O} / \mathrm{CHCl}_{3}$ procedures afforded somewhat equivalent results as the former provided a higher proportion of ions with $\mathrm{CV}$ QC $<30 \%$ in endocellular fractions and vice versa. Considering the nearly equal performances of these approaches, the known carcinogenicity of $\mathrm{CHCl}_{3}{ }^{59}$ streamlined the choice of $\mathrm{MeOH} / \mathrm{H}_{2} \mathrm{O} / \mathrm{MTBE}$ for the definitive experimental setup. A further drawback of chloroform over MTBE is that it might decompose into phosgene and hydrochloric acid which might chemically alter labile lipid species. ${ }^{60}$ Similar mixtures of $\mathrm{MTBE}, \mathrm{MeOH}$ and $\mathrm{H}_{2} \mathrm{O}$ were already reported to simultaneously extract metabolome and lipidome in a satisfying manner. ${ }^{61-63}$ Global metabolomic and lipidomic analyses afforded a comprehensive coverage of the non-polar and polar fractions of HaCaT cells, respectively.

Data quality assurance. With respect to quality control assessments, the following procedures were always applied prior to data acquisition and analysis: comparison of column pressure to that of the previous run, assessment of the internal standard variations between QCs and study samples as well as instrumental stability across the whole batch analyses (in terms of reproducibility of retention times and accurate masses). These criterions guided the acceptance of the analytical strategy undertaken herein. Likewise, retention drift observed throughout the different sequence analyses served as a further ground for the acceptance of the analytical runs.

In lipidomics, the retained external standards were phosphatidylcholine (15:0) (RT 8.37 min), lysophosphatidylcholine (15:0) (RT $1.75 \mathrm{~min}$ ), ceramide (d18:1) (RT $17.95 \mathrm{~min}$ ), C15:0 (RT $3.19 \mathrm{~min}$ ), C23:0 (RT 9.27 min). C17:0 (RT $4.30 \mathrm{~min}$ ) served as an internal standard.

Metabolomic analyses included leucine- $\mathrm{d}_{3}$ (RT $5.97 \mathrm{~min}$ ), tryptophan- $\mathrm{d}_{3}$ (RT $6.10 \mathrm{~min}$ ), indole acetic acid- $\mathrm{d}_{5}(\mathrm{RT}, 1.81 \mathrm{~min})$, tetradecanedioic acid- $\mathrm{d}_{24}(\mathrm{RT} 1.38 \mathrm{~min})$ as external standards. Creatine- $\mathrm{d}_{3}$ (RT $8.22 \mathrm{~min}$ ) and L-lysine- $\mathrm{d}_{4}$ (RT $14.31 \mathrm{~min}$ ) were selected as internal standards.

Peak area and intensity repeatability for the isotope-labeled standards were considered with a threshold of $30 \% \mathrm{CV}$, following the widely admitted idea that ions displaying higher $\mathrm{CV}$ values might not represent fitting candidates when searching for biomarkers. ${ }^{64}$ All isotopelabeled standards fulfilled these conditions, with CV among QC samples being constantly below 15\% (Tables S2 and S3 for lipidomic and metabolomics sequences, respectively). 
Likewise, data sets having greater than $70 \%$ of the ions with CV values among QC samples below $30 \%$ are considered acceptable for further data processing. ${ }^{65,66}$ Depending on the studied fraction, these values ranged between 71.8 and $93.9 \%$ (Table 1), consistently with metabolomics guidelines. ${ }^{65}$

Table 1. Ion features obtained using R-XCMS data processing

\begin{tabular}{|l|l|l|l|l|l|l|}
\hline Metabolome & Fraction & Ion mode & Ions & $\begin{array}{l}\text { Ions with } \\
\text { CV QC }<30 \% \\
\text { (\% of total ions) }\end{array}$ & $\begin{array}{l}\text { Ions } \\
\text { (isotopes) }\end{array}$ & $\begin{array}{l}\text { Ions with } \\
\text { (fold-change }>2 \\
\text { and p-value < 0.05) }\end{array}$ \\
\hline \multirow{3}{*}{ Exo } & \multirow{2}{*}{ Lipido } & Positive & 4125 & $3710(89.9)$ & 2242 & 92 \\
\cline { 3 - 7 } & & Negative & 1129 & $989(87.6)$ & 713 & 29 \\
\cline { 3 - 7 } & \multirow{2}{*}{ Metabo } & Positive & 1838 & $1711(93.1)$ & 1379 & 21 \\
\cline { 3 - 7 } & Legative & 1233 & $1158(93.9)$ & 882 & 63 \\
\hline \multirow{3}{*}{ Lipido } & Positive & 4241 & $3574(84.3)$ & 2182 & 42 \\
\cline { 3 - 7 } & Negative & 1427 & $1024(71.8)$ & 710 & 35 \\
\cline { 3 - 7 } & \multirow{2}{*}{ Metabo } & Positive & 1748 & $1546(88.4)$ & 1290 & 95 \\
\cline { 3 - 7 } & & Negative & 1037 & $925(89.2)$ & 745 & 30 \\
\hline
\end{tabular}

Both these results underscored the reliability of the analytical strategy developed herein.

Extracellular profiles were overwhelmed by the signals arising from 2-DG, failing to reveal any further difference upon exposure to this drug (data not shown). Therefore, only endocellular fraction profiles will be further considered in this manuscript.

Lipidomic RPLC-MS analyses of endocellular fractions. Data processing yielded a number of detected ions aligned by their retention time, accurate masses and peak areas. The data matrix was filtered out as previously indicated, leading to retain 710 and 2182 ions in negative and positive-ion modes, respectively. Establishing PCA loading plots represented a first pertinent step to determine if the metabolic data could successfully separate the two groups. These plots (Figure S1) revealed that control and treated groups clustered separately, whatever the considered ionization mode, indicating distinct metabolic responses between the control and 2-DG-treated groups. The discrimination between sample groups can be made clearer yet when only retaining the features having a Fold-Change $(\mathrm{FC})>2$ with an ANOVA p-value below 0.05 (and a CV QC below 30\%) (Figure S2).

Overall, 42 features in positive-mode and 35 in negative-ion mode were selected as potential biomarkers of exposure to 2-DG (i.e CV among QC samples $<30 \%$, p-value $<0.05$ and fold-change $>2$ ). The careful validation of both Extracted Ion Chromatograms and Box and Whiskers Plot (as described in the Data processing part of the Experimental section) (Figure 3) 
for these putatively dysregulated features led to retain 8 candidate ions as biomarkers of exposure to 2-DG, genuinely corresponding to 6 metabolites (Figure 3, Table 2) as two of these putative biomarkers were found to occur in both positive and negative-ionization modes (M791T825/M827T825 and M819T887/M855T887 (positive-ion mode/negative-ion mode).

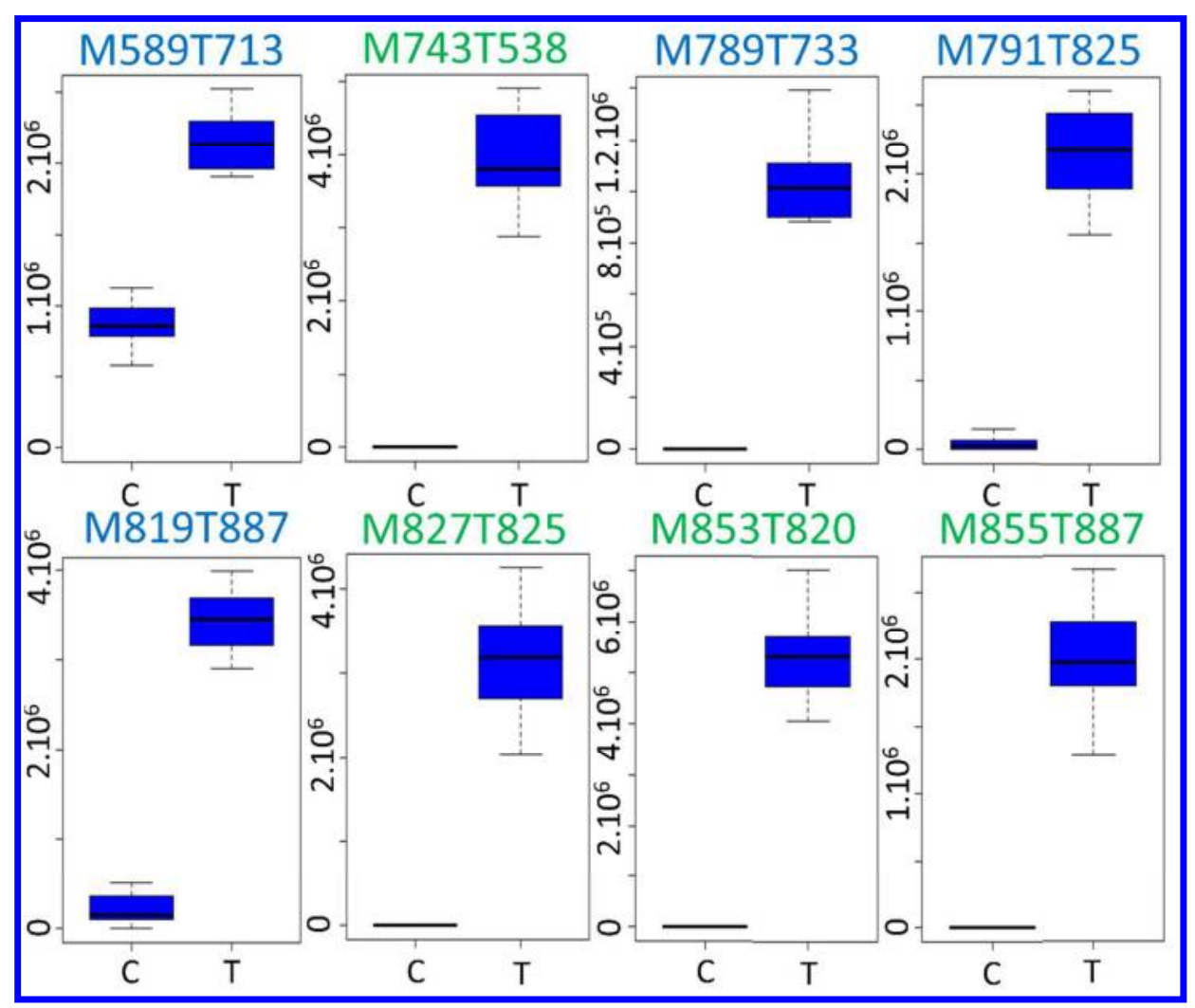

Figure 3. Box and whisker plots of the candidate biomarkers of treatment by 2-DG highlighted by lipidomic RPLC-MS analyses $(n=6)$. The y axis displays the normalized intensity of each metabolite. Features are designated as MXXXTYYY with XXX being the monoisotopic mass and YYY the retention time of the ion. Associated FC and ANOVA p-values are provided in Table 2. Features typed in blue were detected in positive-ion mode and those appearing in green arose in negative polarity.

Accurate mass measurements from these ions were primarily searched against the freely available database LipidMaps, leading to retrieve a list of potential identifications based on previously defined accurate mass error ranges. Further searches were then carried out on METLIN and HMDB to check whether further identifications could be retrieved but none of these databases led to propose other putative hits. All these dysregulated features could thus be identified as a ceramide and different glucosylceramides (Table 2). The biomarker M589T713 could be identified as a $\operatorname{Cer}(36: 1)$, with several putative structures differing in the length and unsaturation degrees of the side chains being possible, as listed in Table 2. From a biological 
viewpoint, all these long-chain ceramides display similar pro-apoptotic and anti-proliferative effects. ${ }^{67,68}$ Ceramides permeabilize the mitochondrial outer membrane, initiating mitochondrialmediated apoptosis through the release of cytochrome c. ${ }^{69}$ Besides this non-protein-mediated signal, a variety of downstream signals involving an array of specific targets also account for ceramide-mediated apoptosis or autophagy. These molecular effects were recently reviewed in the specific context of mammalian epidermidis cells. ${ }^{70}$ Being widely encountered in nature, glucosylceramides are glycolipids bearing a hydrophilic head group sugar, D-glucose, and two hydrophobic aliphatic chains (typically 16 to 26 atoms long) that vary in both length and saturation. ${ }^{71}$ Glycosylceramide synthases are indeed known to convert ceramides into nontoxic glucosylceramides tending to offer cell protection and priming various cell types for proliferation, ${ }^{72-74}$ contributing to convey multi-drug resistance. ${ }^{75,76}$ Owing to these opposite effects, the Cer-to-GlcCer ratio appears to modulate cellular growth versus apoptosis and it was demonstrated that human HaCaT keratinocyte cells might favor ceramide to glucosylceramide conversion to overcome ceramide cytotoxic effects. ${ }^{77}$ Among the 5 glucosylceramides identified as dysregulated in the course of this manuscript, two could be associated with a single hit, i.e M791T825/M827T825 (GlcCer (d18:0/22:0)) and M819T887/M855T887 (GlcCer (d18:0/24:0)). Two glucosylceramide candidates might be responsible for the three remaining hits, preventing us from reaching an unambiguous structural assignment. Nevertheless, the current data enables determining the overall number of carbons and unsaturations of the side chains, granting a sum composition expressed as (total carbons : total double bonds), as suggested by current lipidomic guidelines. $^{78}$ As such, M743T538 could be related to the molecular formula GlcCer $(36: 1)$, M789T733 to GlcCer (40:1) and M853T820 to GlcCer (42:1). The two possible structures for these latter are provided in Table 2. Regarding the biological function of glucosylceramides, their effects were not so far evidenced to depend on the constitution of the fatty acid side chains, not even being shown to vary according to the sum composition of these structures. ${ }^{79}$ Thus, satisfying biological conclusions can be drawn from the biochemical data garnered herein on these biomarkers. Accordingly, in the current study, glucosylceramides were much more upregulated than the identified ceramide which displayed a moderate FC value of 2 (Table 2). The metabolomic study reported herein seems to unveil that $\mathrm{HaCaT}$ keratinocyte cells implement a similar defense strategy. A possible way to validate this putative scenario would be to monitor the expression of these dysregulated features following different times of treatment with 2-DG. One can indeed assume that these up-regulations might refer to a two-step process that would begin with an increase of ceramide to be subsequently counteracted by an increased production of glucosylceramides, as a cytoprotective mechanism. These lipidomic dysregulations are consistent with former studies that reported on the alteration of total levels and/or species 
compositions of several lipid classes. Kavaliauskiene et al. (2015) also reported on an upregulation of ceramide derivatives in HEp-2 cells, which is in line with the outlined results. Conversely, this cellular system also responded by a slight decrease in GlcCer derivatives. ${ }^{80}$ HRMS $^{2}$ analyses might be relevant to distinguish between candidate structures for ambiguous ceramides and glucosylceramides reported herein, indicating the acyl composition of the highlighted biomarkers. Nevertheless, the current knowledge on the role of each one of the lipid molecular species (i.e taking into account the lipid group and exact constitution of the side chains) are too scarce to explain their role on an individual basis. Therefore, it can be surmised that assigning ceramides and glucosylceramides to a sum composition according to the shorthand nomenclature defined by the International Lipid Classification and Nomenclature Committee ${ }^{81}$ provides enough information as to the biological relevance of these dysregulations, as often done elsewhere. $^{82,83}$ 
Table 2. List of potential metabolite candidates dysregulated upon 2-DG treatment, assessed in both positive and negative lipidomic analyses. These putative identifications were obtained after a search in the LipidMaps database with a cutoff of \pm 5 ppm. *HaC: acetic acid. Elemental compositions, theoretical masses and errors for these features are provided in Table S6.

\begin{tabular}{|c|c|c|c|c|c|c|c|}
\hline $\begin{array}{l}\text { RT } \\
\text { (sec.) }\end{array}$ & $\begin{array}{l}\text { Exact mass } \\
\text { (of } m / z \text { signal) }\end{array}$ & LipidMaps hits (0.003 Da) & LipidMaps ID & $\begin{array}{l}\text { Detected ion/Adduct } \\
\text { ion }\end{array}$ & P-value & $\begin{array}{l}\text { Fold- } \\
\text { change }\end{array}$ & $\begin{array}{l}\text { CV QC } \\
(\%)\end{array}$ \\
\hline \multirow[t]{2}{*}{538.13} & \multirow[t]{2}{*}{742.5851} & GlcCer(d16:1(4E)/20:0(2OH)) & LMSP0501AA76 & \multirow[t]{2}{*}[\mathrm{M}-\mathrm{H}]{$^{-}$} & \multirow[t]{2}{*}{$1.3 \mathrm{E}-8$} & \multirow[t]{2}{*}{$\infty$} & \multirow[t]{2}{*}{22.7} \\
\hline & & GlcCer(d14:1(4E)/22:0(2OH)) & LMSP0501AA66 & & & & \\
\hline \multirow[t]{4}{*}{713.41} & \multirow[t]{4}{*}{588.5328} & Cer(d14:1/22:0) & LMSP02010038 & \multirow[t]{4}{*}[\mathrm{M}+\mathrm{Na}]{$^{+}$} & \multirow[t]{4}{*}{$2.3 \mathrm{E}-10$} & \multirow[t]{4}{*}{2.0} & \multirow[t]{4}{*}{6.4} \\
\hline & & Cer(d16:1/20:0) & LMSP02010047 & & & & \\
\hline & & Cer(d18:0/18:1) & LMSP02020015 & & & & \\
\hline & & Cer(d18:1/18:0) & LMSP02010006 & & & & \\
\hline \multirow[t]{2}{*}{733.12} & \multirow[t]{2}{*}{788.6332} & GlcCer(d16:1/24:0) & LMSP0501AA51 & \multirow[t]{2}{*}[\mathrm{M}-\mathrm{H}_{2}\mathrm{O}+\mathrm{Na}]{$^{+}$} & \multirow[t]{2}{*}{$3.0 \mathrm{E}-7$} & \multirow[t]{2}{*}{90.2} & \multirow[t]{2}{*}{28.2} \\
\hline & & GlcCer(d18:1/22:0) & LMSP0501AA07 & & & & \\
\hline \multirow[t]{2}{*}{819.99} & \multirow[t]{2}{*}{852.6941} & GlcCer(d18:0(4E)/24:1(15Z)) & LMSP0501AA22 & \multirow[t]{2}{*}[\mathrm{M}-\mathrm{H}_{2}\mathrm{O}+\mathrm{HaC}-\mathrm{H}]{$^{-*}$} & \multirow[t]{2}{*}{$1.0 \mathrm{E}-8$} & \multirow[t]{2}{*}{$\infty$} & \multirow[t]{2}{*}{13.9} \\
\hline & & GlcCer(d18:1/24:0) & LMSP0501AA09 & & & & \\
\hline 825.01 & 790.6478 & \multirow[t]{2}{*}{ GlcCer(d18:0/22:0) } & \multirow[t]{2}{*}{ LMSP0501AA21 } & {$\left[\mathrm{M}-\mathrm{H}_{2} \mathrm{O}+\mathrm{Na}\right]^{+}$} & $3.0 \mathrm{E}-9$ & 4.1 & 26.4 \\
\hline 825.37 & 826.6782 & & & {$\left[\mathrm{M}-\mathrm{H}_{2} \mathrm{O}+\mathrm{HaC}-\mathrm{H}\right]^{-*}$} & $1.6 \mathrm{E}-7$ & $\infty$ & 18.7 \\
\hline 887.13 & 818.6823 & \multirow[t]{2}{*}{ GlcCer(d18:0/24:0) } & \multirow[t]{2}{*}{ LMSP0501AA23 } & {$\left[\mathrm{M}-\mathrm{H}_{2} \mathrm{O}+\mathrm{Na}\right]^{+}$} & $2.3 \mathrm{E}-13$ & 15.3 & 15.5 \\
\hline 887.43 & 854.7089 & & & {$\left[\mathrm{M}-\mathrm{H}_{2} \mathrm{O}+\mathrm{HaC}-\mathrm{H}\right]^{-*}$} & $1.7 \mathrm{E}-7$ & $\infty$ & 0 \\
\hline
\end{tabular}


Metabolomic HILIC-MS analyses of endocellular fractions. Irrespective of the ionization mode, PCA plots failed to reveal a clear cut separation when all $\mathrm{m} / \mathrm{z}$ signals were used (Figure S3). Nevertheless, when only plotting the significantly altered $m / z$ values upon 2 DG exposure (i.e p-value $<0.05$ and fold-change $>2$ with $\mathrm{CV}$ among QC samples $<30 \%$ ), PCA plots resulted in a satisfying discrimination in both ion modes (Figure S4). As reported in Table 1, this filtered data set corresponded to 95 and 30 features in positive and negative-ion modes, respectively. Data processing and analysis emphasized 7 molecular features as major contributors to the variance between treated and control cells (Figure 4, Table 3). These metabolites of interest were tentatively identified against METLIN and HMDB databases which could lead to propose putative identifications for all 7 features. Among these ions, only one, M277T435/M289T441, indicated a clear-cut dysregulation between the two sample groups, as previously reported for lipidomic sequences (Figure 4). This metabolite could be tentatively identified as galactosylglycerol but the biological relevance of this dysregulation still remains to be determined. With respect to the six remaining features, multiple putative identifications could be retrieved from freely available databases. Overall, these hits could be identified as phosphatidylcholine or phosphatidylethanolamine derivatives (Tables 3 and S4). More precisely, three biomarkers M809T320/M821T328, M719T328 and M747T329 could be related to this former class of lipids. Conversely, M751T169 could be identified as a phosphatidylethanolamine derivative. Regarding the two last biomarkers highlighted throughout the lipidomic workflow, putative hits could be retrieved from both phosphatidylcholine and phosphatidylethanolamine series. Generated results were assessed by regards to their physicochemical properties. Taking into account $\log \mathrm{P}$ values could narrow down the identification possibilities for these metabolites leading to tentatively identified them either as a phosphatidylethanolamine or a phosphatidylcholine derivative (Table S5). As to M719T191, LogP values associated with the phosphatidylcholine candidates are not in line with the retention time obtained for this feature. Likewise, phosphatidylethanolamine candidates proposed for M761T326/M795T331 are too apolar to fit the retention time of this feature. Therefore, it can be assumed that M719T191 might stand for a phosphatidylethanolamine derivative and that M761T326/M795T331 corresponds to a further phosphatidylcholine-derived metabolite. Altogether, these data can lead to define a list of possible biomarkers related to a single structural series for all dysregulated features. Even though the lack of these substances as commercially available standards precluded the individual identification of these metabolites, each feature could be associated with a global number of carbons for the two side chains as well as an overall number of unsaturations, as earlier described for ceramide and glucosylceramide derivatives (Table 3). The close physicochemical properties and identical matrices of occurrence precluded unambiguous structural assignments among the 
remaining candidates. Further $\mathrm{HRMS}^{2}$ analyses might be relevant to further discriminate between the possible candidates garnered in Table 3 even though reaching unambiguous structural assignments might be very hard to achieve, owing to the multiple possible positions of unsaturations, in particular. Not being able to discriminate among putative glycerophospholipids displaying an identical number of carbons and unsaturations is not believed to represent a severe limitation of the current work. Indeed, phosphatidylcholines represent a highly complex family of 1,2-diacylglycerophospholipids, that are mainly known through their structural role as essential components of cell membranes. These metabolites have in common a zwitterionic structure comprising hydrophobic side chains differing in their lengths and unsaturation degrees. So far, the biological role of these glycerophospholipids has been primarily defined by regards to the overall chain length and not an individual molecule basis. ${ }^{84}$ Accordingly, metabolomic investigations reporting on perturbations of glycerophospholipid content often define the global number of carbons and number of double bonds, as performed here. ${ }^{85-87}$ As to the dysregulated phosphatidylethanolamine derivatives, it is worth noting that they display an identical number of carbons and unsaturations than phosphatidylcholine derivatives emphasized herein. Therefore, the former might represent biosynthetic intermediates en route to the latter. ${ }^{88}$ Moreover, the level of these phosphatidylcholine and phosphatidylethanolamine derivatives are only poorly altered after 2-DG treatment with FC being always comprised between 2 and 3, so these effects might not be of paramount importance to understand the effects of this cytotoxic drug, further limiting the interest of reaching an unambiguous structural assignment of these features. 
Table 3. List of potential metabolite candidates dysregulated upon 2-DG treatment, assessed in both positive and negative metabolomic analyses. These putative identifications were obtained after a search in the HMDB database with a cutoff of \pm 5 ppm. Associated FC and ANOVA p-values are provided in Table 2.*HMDB hits indicated between brackets display inconsistent physicochemical parameters (Table S5). ** Owing to the elevated number of candidates, the exact references of hits along with the associated HMDB IDs are collated in Table S4. Elemental compositions, theoretical masses and errors for these features are provided in Table S7.

\begin{tabular}{|c|c|c|c|c|c|c|c|}
\hline $\begin{array}{l}\mathrm{RT} \\
\text { (sec.) }\end{array}$ & $\begin{array}{l}\text { Exact mass } \\
\text { (of } m / z \text { signal) }\end{array}$ & HMDB hits & HMDB ID & $\begin{array}{l}\text { Detected ion/Adduct } \\
\text { ion }\end{array}$ & P-value & $\begin{array}{l}\text { Fold- } \\
\text { change }\end{array}$ & $\begin{array}{l}\text { CV QC } \\
(\%)\end{array}$ \\
\hline \multirow[t]{2}{*}{168.96} & \multirow[t]{2}{*}{750.5417} & PE (38:5) & $* *$ & {$[\mathrm{M}+\mathrm{H}]^{+}$} & \multirow[t]{2}{*}{0.009} & \multirow[t]{2}{*}{2.8} & \multirow[t]{2}{*}{25.1} \\
\hline & & PE (36:2) & $* *$ & {$[\mathrm{M}+\mathrm{Na}]^{+}$} & & & \\
\hline 190.99 & 718.5370 & $\begin{array}{l}\text { PE }(34: 1) \\
\text { PC }(31: 1)^{*}\end{array}$ & $* *$ & {$[\mathrm{M}+\mathrm{H}]^{+}$} & 0.009 & 2.5 & 27.1 \\
\hline 320.48 & 808.5834 & \multirow[t]{2}{*}{ PC (36:2) } & \multirow[t]{2}{*}{$* *$} & {$[\mathrm{M}+\mathrm{Na}]^{+}$} & 0.006 & 2.1 & 4 \\
\hline 327.58 & 820.5603 & & & {$[\mathrm{M}+\mathrm{Cl}]^{-}$} & 0.004 & 2.5 & 26.1 \\
\hline 326.18 & 760.5840 & \multirow{2}{*}{$\begin{array}{l}\text { PC }(34: 1) \\
\text { PE }(37: 1)^{*}\end{array}$} & \multirow[t]{2}{*}{$* *$} & {$[\mathrm{M}+\mathrm{H}]^{+}$} & 0.004 & 2.1 & 5.7 \\
\hline 331.13 & 794.5475 & & & {$[\mathrm{M}+\mathrm{Cl}]^{-}$} & 0.004 & 2.1 & 9.1 \\
\hline 328.30 & 718.5775 & PC (32:0) & $* *$ & {$[\mathrm{M}+\mathrm{H}]^{+}$} & 0.004 & 2.2 & 8.5 \\
\hline 328.92 & 746.6057 & PC (34:0) & $* *$ & {$[\mathrm{M}+\mathrm{H}]^{+}$} & 0.002 & 2.5 & 8.6 \\
\hline 435.15 & 277.0891 & \multirow[t]{2}{*}{ Galactosylglycerol } & \multirow[t]{2}{*}{ HMDB06790 } & {$[\mathrm{M}+\mathrm{Na}]^{+}$} & $1.3 \mathrm{E}-8$ & 1035 & 22.5 \\
\hline 441.00 & 289.0700 & & & {$[\mathrm{M}+\mathrm{Cl}]^{-}$} & $1.7 \mathrm{E}-5$ & 228 & 28.3 \\
\hline
\end{tabular}




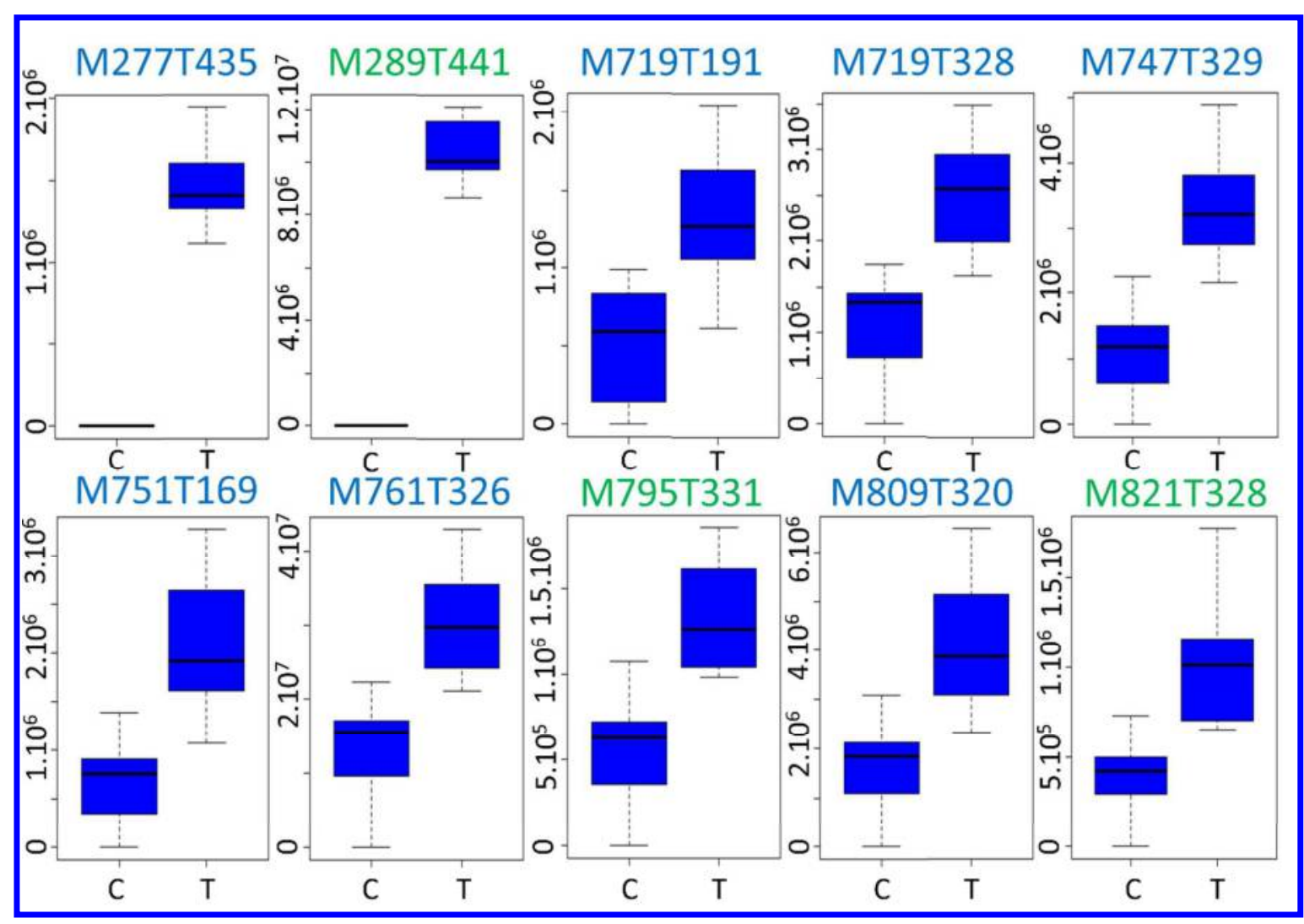

Figure 4. Box and whisker plots of the candidate biomarkers of challenge to 2-DG revealed by metabolomic HILIC analyses $(n=6)$. Features are designated as MXXXTYYY with XXX being the monoisotopic mass and YYY the retention time of the ion. Associated FC and ANOVA pvalues are provided in Table 3. Features typed in blue were detected in positive-ion mode and those appearing in green arose in negative polarity.

\section{CONCLUSION}

The analytical strategy described herein streamlined the delineation of 13 features (6 lipids and 7 metabolites) as biomarkers of acute exposure to 2-DG, thereby proving the adequacy of the proposed workflow for metabolomics. Lipidomic analyses unveiled that 2-DG mainly altered the metabolism of a ceramide, the moderate elevation of this pro-apoptotic lipid being accompanied by a dramatic increase of the concentration of the pro-mitogenic glucosylceramides, which might be interpreted as a cytoprotective mechanism to circumvent the cytotoxicity of the former. These outcomes are consistent with former reports. Besides, metabolomic analyses revealed a tremendous increase of galactosylglycerol as well as slight elevations of several phosphatidylethanolamine and phosphatidylcholine derivatives. The current study was performed on a single HRMS analyzer including any limitation coming along with it. In such conditions, no structural resolution of the composite fatty acids is available, supporting an annotation by sum composition, as defined by lipidomics harmonizing guidelines, thus failing to 
reach a single tentative candidate in cases where several hits were retrieved from databases. Nevertheless, this limitation is not believed to represent a severe hindrance to decipher the biological relevance of the dysregulated features outlined in this manuscript since the functional roles of the lipid classes reported herein are not yet established on an individual molecular basis but rather rely on lipid species group (i.e long-chain ceramides vs very-long chain ceramides). More generally speaking, lipid identification is widely regarded as the most challenging step in the lipidomic workflow owing to the molecular complexity of the lipidome. Accordingly, hyphenated strategies are increasingly being implemented in traditional lipidomic pipelines to increase the confidence of lipid identification such as tandem mass spectrometric analyses that are very often required to distinguish structures among numerous isobaric species or ion mobility-mass spectrometry.

\section{ACKNOWLEDGMENTS}

The authors are indebted to the French Agency for Food, Environmental and Occupational Health and Society (ANSES) for having funded this study through the project BEMAM (BioElectroMagnétisme et Analyse Métabolomique - $\mathrm{n}^{\circ}$ EST-2014/2 RF/012). Metabolomic analyses used the instrumental facilities of LABERCA (Nantes).

\section{SUPPORTING INFORMATION}

The following files are available free of charge at ACS website http://pubs.acs.org:

Figure S1. PCA plots obtained from endocellular lipidomics sequences from the whole set of features. Figure S2. PCA plots obtained from endocellular lipidomics sequences using a filtered data set (features having both fold-change $>2$, p-value $<0.05$ and CV QC $<30 \%$ ). Figure S3. PCA plots obtained from endocellular metabolomics sequences from the whole set of features. Figure S4. PCA plots obtained from endocellular lipidomics sequences from filtered data set (features having both fold-change $>2$, p-value $<0.05$ and CV QC $<30 \%$ ). Table S1. Comparison of extraction procedures involving several solvent systems (R-XCMS data processing). Table S2. CV values of internal and external standards among QC samples in lipidomic sequences. Table S3. CV values of internal and external standards among QC samples in metabolomic sequences. Table S4. Tentative identification of metabolites dysregulated upon 2-DG treatment. Table S5. Theoretical LogP values of putative metabolites identified during metabolomic sequences. Red-typed values are not consistent with the retention time of the feature. Table S6. Summary of the data from the 8 features found significant in the comparisons 2-DG vs Sham-exposed sample groups (lipidomics). Table S7. Summary of the data from the 8 
features found significant in the comparisons 2-DG vs Sham-exposed sample groups (metabolomics).

\section{References}

(1) Vander Heiden, M. G.; Cantley, L. C.; Thompson, C. B. Understanding the Warburg Effect: The Metabolic Requirements of Cell Proliferation. Science 2009, 324 (5930), 1029-1033.

(2) Hanahan, D.; Weinberg, R. A. Hallmarks of cancer: the next generation. Cell 2011, 144 (5), 646674.

(3) Liu, H.; Hu, Y. P.; Savaraj, N.; Priebe, W.; Lampidis, T. J. Hypersensitization of Tumor Cells to Glycolytic Inhibitors ${ }^{\dagger}$. Biochemistry (Mosc.) 2001, 40 (18), 5542-5547.

(4) Liu, H.; Savaraj, N.; Priebe, W.; Lampidis, T. J. Hypoxia increases tumor cell sensitivity to glycolytic inhibitors: a strategy for solid tumor therapy (Model C). Biochem. Pharmacol. 2002, 64 (12), 1745-1751.

(5) Pelicano, H.; Martin, D. S.; Xu, R.-H.; Huang, P. Glycolysis inhibition for anticancer treatment. Oncogene 2006, 25 (34), 4633-4646.

(6) Xu, R.; Pelicano, H.; Zhou, Y.; Carew, J. S.; Feng, L.; Bhalla, K. N.; Keating, M. J.; Huang, P. Inhibition of glycolysis in cancer cells: a novel strategy to overcome drug resistance associated with mitochondrial respiratory defect and hypoxia. Cancer Res. 2005, 65 (2), 613-621.

(7) Stein, M.; Lin, H.; Jeyamohan, C.; Dvorzhinski, D.; Gounder, M.; Bray, K.; Eddy, S.; Goodin, S.; White, E.; DiPaola, R. S. Targeting tumor metabolism with 2-deoxyglucose in patients with castrate-resistant prostate cancer and advanced malignancies. The Prostate 2010, 70 (13), 13881394.

(8) Singh, D.; Banerji, A. K.; Dwarakanath, B. S.; Tripathi, R. P.; Gupta, J. P.; Mathew, T. L.; Ravindranath, T.; Jain, V. Optimizing Cancer Radiotherapy with 2-Deoxy-D-Glucose: Dose Escalation Studies in Patients with Glioblastoma Multiforme. Strahlenther. Onkol. 2005, 181 (8), 507-514.

(9) Mohanti, B. K.; Rath, G. K.; Anantha, N.; Kannan, V.; Das, B. S.; Chandramouli, B. A.; Banerjee, A. K.; Das, S.; Jena, A.; Ravichandran, R.; et al. Improving cancer radiotherapy with 2-deoxy-Dglucose: phase I/II clinical trials on human cerebral gliomas. Int. J. Radiat. Oncol. Biol. Phvs. 1996, 35 (1), 103-111.

(10) Raez, L. E.; Papadopoulos, K.; Ricart, A. D.; Chiorean, E. G.; DiPaola, R. S.; Stein, M. N.; Rocha Lima, C. M.; Schlesselman, J. J.; Tolba, K.; Langmuir, V. K.; et al. A phase I dose-escalation trial of 2-deoxy-d-glucose alone or combined with docetaxel in patients with advanced solid tumors. Cancer Chemother. Pharmacol. 2013, 71 (2), 523-530.

(11) Ralser, M.; Wamelink, M. M.; Struys, E. A.; Joppich, C.; Krobitsch, S.; Jakobs, C.; Lehrach, H. A catabolic block does not sufficiently explain how 2-deoxy-D-glucose inhibits cell growth. Proc. Natl. Acad. Sci. 2008, 105 (46), 17807-17811.

(12) O'Donnell, A. F.; McCartney, R. R.; Chandrashekarappa, D. G.; Zhang, B. B.; Thorner, J.; Schmidt, M. C. 2-Deoxyglucose Impairs Saccharomyces cerevisiae Growth by Stimulating Snf1-Regulated and $\alpha$-Arrestin-Mediated Trafficking of Hexose Transporters 1 and 3. Mol. Cell. Biol. 2015, 35 (6), 939-955.

(13) Kang, H. T.; Hwang, E. S. 2-Deoxyglucose: An anticancer and antiviral therapeutic, but not any more a low glucose mimetic. Life Sci. 2006, 78 (12), 1392-1399.

(14) McCartney, R. R.; Chandrashekarappa, D. G.; Zhang, B. B.; Schmidt, M. C. Genetic Analysis of Resistance and Sensitivity to 2-Deoxyglucose in Saccharomyces cerevisiae. Genetics 2014, 198 (2), 635-646.

(15) Jaspers, H. T. A.; Van Steveninck, J. Transport-associated phosphorylation of 2-deoxy-D-glucose in Saccharomyces fragilis. Biochim. Biophvs. Acta BBA-Biomembr. 1975, 406 (3), 370-385.

(16) Loba, Z.; Maitra, P. K. Resistance to 2-deoxyglucose in yeast: a direct selection of mutants lacking glucose-phosphorylating enzymes. Mol. Gen. Genet. MGG 1977, 157 (3), 297-300.

(17) Farkaš, V.; Svoboda, A.; Bauer, Š. Secretion of cell-wall glycoproteins by yeast protoplasts. Effect of 2-deoxy-D-glucose and cycloheximide. Biochem. J. 1970, 118 (5), 755-758. 
(18) Kratky, Z.; Biely, P.; Bauer, Š. Mechanism of 2-Deoxy-d-glucose Inhibition of Cell-Wall Polysaccharide and Glycoprotein Biosyntheses in Saccharomyces cerevisiae. Eur. J. Biochem. 1975, 54 (2), 459-467.

(19) Datema, R.; Schwarz, R. T. Formation of 2-Deoxyglucose-Containing Lipid-Linked Oligosaccharides. Eur. J. Biochem. 1978, 90 (3), 505-516.

(20) Xi, H.; Kurtoglu, M.; Liu, H.; Wangpaichitr, M.; You, M.; Liu, X.; Savaraj, N.; Lampidis, T. J. 2-Deoxy$\mathrm{d}$-glucose activates autophagy via endoplasmic reticulum stress rather than ATP depletion. Cancer Chemother. Pharmacol. 2011, 67 (4), 899-910.

(21) Xi, H.; Barredo, J. C.; Merchan, J. R.; Lampidis, T. J. Endoplasmic reticulum stress induced by 2deoxyglucose but not glucose starvation activates AMPK through CaMKK $\beta$ leading to autophagy. Biochem. Pharmacol. 2013, 85 (10), 1463-1477.

(22) Ramirez-Peinado, S.; Alcazar-Limones, F.; Lagares-Tena, L.; El Mjiyad, N.; Caro-Maldonado, A.; Tirado, O. M.; Munoz-Pinedo, C. 2-Deoxyglucose Induces Noxa-Dependent Apoptosis in Alveolar Rhabdomyosarcoma. Cancer Res. 2011, 71 (21), 6796-6806.

(23) Soubere Mahamoud, Y.; Aite, M.; Martin, C.; Zhadobov, M.; Sauleau, R.; Le Dréan, Y.; Habauzit, D. Additive Effects of Millimeter Waves and 2-Deoxyglucose Co-Exposure on the Human Keratinocyte Transcriptome. PLOS ONE 2016, 11 (8), e0160810.

(24) Čuperlović-Culf, M.; Barnett, D. A.; Culf, A. S.; Chute, I. Cell culture metabolomics: applications and future directions. Drua Discov. Todav 2010, 15 (15), 610-621.

(25) Ceglarek, U.; Shackleton, C.; Stancyk, F. Z.; Adamski, J. Steroid profiling and analytics: going towards sterome. J. Steroid Biochem. Mol. Biol. 2010, 121, 479-480.

(26) Wang-Sattler, R.; Yu, Y.; Mittelstrass, K.; Lattka, E.; Altmaier, E.; Gieger, C.; Ladwig, K. H.; Dahmen, N.; Weinberger, K. M.; Hao, P.; et al. Metabolic Profiling Reveals Distinct Variations Linked to Nicotine Consumption in Humans - First Results from the KORA Study. PLOS ONE 2008, 3 (12), e3863.

(27) Altmaier, E.; Kastenmüller, G.; Römisch-Margl, W.; Thorand, B.; Weinberger, K. M.; Adamski, J.; Illig, T.; Döring, A.; Suhre, K. Variation in the human lipidome associated with coffee consumption as revealed by quantitative targeted metabolomics. Mol. Nutr. Food Res. 2009, 53 (11), 13571365.

(28) Kell, D. B.; Goodacre, R. Metabolomics and systems pharmacology: why and how to model the human metabolic network for drug discovery. Drua Discov. Todav 2014, 19 (2), 171-182.

(29) Sreekumar, A.; Poisson, L. M.; Rajendiran, T. M.; Khan, A. P.; Cao, Q.; Yu, J.; Laxman, B.; Mehra, R.; Lonigro, R. J.; Li, Y.; et al. Metabolomic profiles delineate potential role for sarcosine in prostate cancer progression. Nature 2009, 457 (7231), 910-914.

(30) Misek, D. E.; Kim, E. H. Protein Biomarkers for the Early Detection of Breast Cancer. Int. J. Proteomics 2011, 2011, 1-9.

(31) Wang-Sattler, R.; Yu, Z.; Herder, C.; Messias, A. C.; Floegel, A.; He, Y.; Heim, K.; Campillos, M.; Holzapfel, C.; Thorand, B.; et al. Novel biomarkers for pre-diabetes identified by metabolomics. Mol. Syst. Biol. 2012, 8, 615 .

(32) Hyötyläinen, T. Novel methodologies in metabolic profiling with a focus on molecular diagnostic applications. Expert Rev. Mol. Diagn. 2012, 12 (5), 527-538.

(33) Dunn, W. B.; Ellis, D. I. Metabolomics: Current analytical platforms and methodologies. $\operatorname{TrAC}$ Trends Anal. Chem. 2005, 24 (4), 285-294.

(34) Folch, J.; Lees, M.; Sloane Stanley, G. H. A simple method for the isolation and purification of total lipides from animal tissues. J. Biol. Chem. 1957, 226, 497-509.

(35) Bligh, E. G.; Dyer, W. J. A rapid method of total lipid extraction and purification. Can. J. Biochem. Physiol. 1959, 37 (8), 911-917.

(36) Watson, A. D. Thematic review series: Systems Biology Approaches to Metabolic and Cardiovascular Disorders. Lipidomics: a global approach to lipid analysis in biological systems. $\underset{\underline{J}}{.}$ Lipid Res. 2006, 47 (10), 2101-2111.

(37) Dettmer, K.; Nürnberger, N.; Kaspar, H.; Gruber, M. A.; Almstetter, M. F.; Oefner, P. J. Metabolite extraction from adherently growing mammalian cells for metabolomics studies: optimization of harvesting and extraction protocols. Anal. Bioanal. Chem. 2011, 399 (3), 1127-1139. 
(38) Matyash, V.; Liebisch, G.; Kurzchalia, T. V.; Shevchenko, A.; Schwudke, D. Lipid extraction by methyl-tert-butyl ether for high-throughput lipidomics. J. Lipid Res. 2008, 49 (5), 1137-1146.

(39) Xiao, J. F.; Zhou, B.; Ressom, H. W. Metabolite identification and quantitation in LC-MS/MS-based metabolomics. TrAC Trends Anal. Chem. 2012, 32, 1-14.

(40) Trygg, J.; Holmes, E.; Lundstedt, T. Chemometrics in metabonomics. J. Proteome Res. 2007, 6 (2), 469-479.

(41) Le Quément, C.; Nicolaz, C. N.; Habauzit, D.; Zhadobov, M.; Sauleau, R.; Le Dréan, Y. Impact of 60$\mathrm{GHz}$ millimeter waves and corresponding heat effect on endoplasmic reticulum stress sensor gene expression: ER Stress Under MMW Exposure. Bioelectromaanetics 2014, 35 (6), 444-451.

(42) Halama, A. Metabolomics in cell culture-A strategy to study crucial metabolic pathways in cancer development and the response to treatment. Arch. Biochem. Biophvs. 2014, 564, 100109.

(43) Kerdivel, G.; Boudot, A.; Habauzit, D.; Percevault, F.; Demay, F.; Pakdel, F.; Flouriot, G. Activation of the MKL1/actin signaling pathway induces hormonal escape in estrogen-responsive breast cancer cell lines. Mol. Cell. Endocrinol. 2014, 390 (1-2), 34-44.

(44) León, Z.; García-Cañaveras, J. C.; Donato, M. T.; Lahoz, A. Mammalian cell metabolomics: Experimental design and sample preparation. Electrophoresis 2013, 34, 2762-2775.

(45) Batista, U.; Garvas, M.; Nemec, M.; Schara, M.; Veranič, P.; Koklic, T. Effects of different detachment procedures on viability, nitroxide reduction kinetics and plasma membrane heterogeneity of V-79 cells. Cell Biol. Int. 2010, 34 (6), 663-668.

(46) Paglia, G.; Hrafnsdóttir, S.; Magnúsdóttir, M.; Fleming, R. M. T.; Thorlacius, S.; Palsson, B. Ø.; Thiele, I. Monitoring metabolites consumption and secretion in cultured cells using ultraperformance liquid chromatography quadrupole-time of flight mass spectrometry (UPLC-Q-ToFMS). Anal. Bioanal. Chem. 2012, 402 (3), 1183-1198.

(47) Wehrens, R.; Hageman, J. A.; van Eeuwijk, F.; Kooke, R.; Flood, P. J.; Wijnker, E.; Keurentjes, J. J. B.; Lommen, A.; van Eekelen, H. D. L. M.; Hall, R. D.; et al. Improved batch correction in untargeted MS-based metabolomics. Metabolomics 2016, 12 (5), 88.

(48) Brunius, C.; Shi, L.; Landberg, R. Large-scale untargeted LC-MS metabolomics data correction using between-batch feature alignment and cluster-based within-batch signal intensity drift correction. Metabolomics 2016, 12 (11), 173.

(49) Chetwynd, A. J.; Abdul-Sada, A.; Holt, S. G.; Hill, E. M. Use of a pre-analysis osmolality normalisation method to correct for variable urine concentrations and for improved metabolomic analyses. J. Chromatogr. A 2016, 1431, 103-110.

(50) Smith, C. A.; Want, E. J.; O'Maille, G.; Abagyan, R.; Siuzdak, G. XCMS: Processing Mass Spectrometry Data for Metabolite Profiling Using Nonlinear Peak Alignment, Matching, and Identification. Anal. Chem. 2006, 78 (3), 779-787.

(51) Smith, C. A.; O'Maille, G.; Want, E. J.; Qin, C.; Trauger, S. A.; Brandon, T. R.; Custodio, D. E.; Abagyan, R.; Siuzdak, G. METLIN: a metabolite mass spectral database. Ther. Drua Monit. 2005, $27(6), 747-751$.

(52) Tautenhahn, R.; Patti, G. J.; Rinehart, D.; Siuzdak, G. XCMS Online: A Web-Based Platform to Process Untargeted Metabolomic Data. Anal. Chem. 2012, 84 (11), 5035-5039.

(53) Wishart, D. S.; Tzur, D.; Knox, C.; Eisner, R.; Guo, A. C.; Young, N.; Cheng, D.; Jewell, K.; Arndt, D.; Sawhney, S.; et al. HMDB: the Human Metabolome Database. Nucleic Acids Res. 2007, 35 (Database), D521-D526.

(54) Wishart, D. S.; Jewison, T.; Guo, A. C.; Wilson, M.; Knox, C.; Liu, Y.; Djoumbou, Y.; Mandal, R.; Aziat, F.; Dong, E.; et al. HMDB 3.0--The Human Metabolome Database in 2013. Nucleic Acids Res. 2013, 41 (D1), D801-D807.

(55) Fahy, E.; Subramaniam, S.; Murphy, R. C.; Nishijima, M.; Raetz, C. R. H.; Shimizu, T.; Spener, F.; van Meer, G.; Wakelam, M. J. O.; Dennis, E. A. Update of the LIPID MAPS comprehensive classification system for lipids. J. Lipid Res. 2008, 50 (Supplement), S9-S14.

(56) Nicolas Nicolaz, C.; Zhadobov, M.; Desmots, F.; Sauleau, R.; Thouroude, D.; Michel, D.; Le Drean, Y. Absence of direct effect of low-power millimeter-wave radiation at $60.4 \mathrm{GHz}$ on endoplasmic reticulum stress. Cell Biol. Toxicol. 2009, 25 (5), 471-478. 
(57) Ikeda, J.; Kaneda, S.; Kuwabara, K.; Ogawa, S.; Kobayashi, T.; Matsumoto, M.; Yura, T.; Yanagi, H. Cloning and expression of cDNA encoding the human $150 \mathrm{kDa}$ oxygen-regulated protein, ORP150. Biochem. Biophvs. Res. 1997, 230 (1), 94-99.

(58) Zhang, H.; Lu, M.; Qi, H. B.; Zhang, J. H. Up-regulation of glucose regulated protein 78 induced by 2-deoxy-glucose plays a protective role for fetal rat cerebral neuron following intrauterine distress. Zhonahua Fu Chan Ke Za Zhi 2008, 43, 356-360.

(59) Nagano, K.; Kano, H.; Arito, H.; Yamamoto, S.; Matsushima, T. Enhancement of Renal Carcinogenicity by Combined Inhalation and Oral Exposures to Chloroform in Male Rats. J. Toxicol. Environ. Health A 2006, 69 (20), 1827-1842.

(60) Schmid, P.; Hunter, E.; Calvert, J. Extraction and purification of lipids. III. Serious limitations of chloroform and chloroform-methanol in lipid investigations. Physiol. Chem. Phys. Med. NMR 1973, 5, 151-155.

(61) Li, L.; Lu, X.; Zhao, J.; Zhang, J.; Zhao, Y.; Zhao, C.; Xu, G. Lipidome and metabolome analysis of fresh tobacco leaves in different geographical regions using liquid chromatography-mass spectrometry. Anal. Bioanal. Chem. 2015, 407 (17), 5009-5020.

(62) Li, L.; Zhao, J.; Zhao, Y.; Lu, X.; Zhou, Z.; Zhao, C.; Xu, G. Comprehensive investigation of tobacco

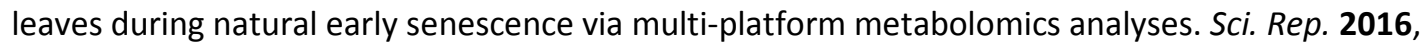
$6(1), 37976$.

(63) Cajka, T.; Fiehn, O. Toward Merging Untargeted and Targeted Methods in Mass SpectrometryBased Metabolomics and Lipidomics. Anal. Chem. 2016, 88 (1), 524-545.

(64) Kouassi Nzoughet, J.; Bocca, C.; Simard, G.; Prunier-Mirebeau, D.; Chao de la Barca, J. M.; Bonneau, D.; Procaccio, V.; Prunier, F.; Lenaers, G.; Reynier, P. A Nontargeted UHPLC-HRMS Metabolomics Pipeline for Metabolite Identification: Application to Cardiac Remote Ischemic Preconditioning. Anal. Chem. 2017, 89 (3), 2138-2146.

(65) Want, E. J.; Wilson, I. D.; Gika, H.; Theodoridis, G.; Plumb, R. S.; Shockcor, J.; Holmes, E.; Nicholson, J. K. Global metabolic profiling procedures for urine using UPLC-MS. Nat. Protoc. 2010, 5, 1005-1018.

(66) Kim, N.; Ryu, S. M.; Lee, D.; Lee, J. W.; Seo, E.-K.; Lee, J.-H.; Lee, D. A metabolomic approach to determine the geographical origins of Anemarrhena asphodeloides by using UPLC-QTOF MS. . Pharm. Biomed. Anal. 2014, 92, 47-52.

(67) Grösch, S.; Schiffmann, S.; Geisslinger, G. Chain length-specific properties of ceramides. Proa. Lipid Res. 2012, 51 (1), 50-62.

(68) Pettus, B. J.; Chalfant, C. E.; Hannun, Y. A. Ceramide in apoptosis: an overview and current perspectives. Biochim. Biophvs. Acta BBA-Mol. Cell Biol. Lipids 2002, 1585 (2), 114-125.

(69) Siskind, L. J.; Kolesnick, R. N.; Colombini, M. Ceramide Channels Increase the Permeability of the Mitochondrial Outer Membrane to Small Proteins. J. Biol. Chem. 2002, 277 (30), 26796-26803.

(70) Uchida, Y. Ceramide signaling in mammalian epidermis. Biochim. Biophvs. Acta BBA - Mol. Cell Biol. Lipids 2014, 1841 (3), 453-462.

(71) Bleicher, R. J.; Cabot, M. C. Glucosylceramide synthase and apoptosis. Biochim. Biophvs. Acta BBA-Mol. Cell Biol. Lipids 2002, 1585 (2), 172-178.

(72) Datta, S. C.; Radin, N. S. Stimulation of liver growth and DNA synthesis by glucosylceramide. Lipids 1988, 23 (5), 508-510.

(73) Shayman, J. A.; Deshmukh, G. D.; Mahdiyoun, S.; Thomas, T. P.; Wu, D.; Barcelon, F. S.; Radin, N. $S$. Modulation of renal epithelial cell growth by glucosylceramide. Association with protein kinase C, sphingosine, and diacylglycerol. J. Biol. Chem. 1991, 266, 22968-22974.

(74) Marchell, N. L.; Uchida, Y.; Brown, B. E.; Elias, P. M.; Holleran, W. M. Glucosylceramides Stimulate Mitogenesis in Aged Murine Epidermis. J. Invest. Dermatol. 1998, 110 (4), 383-387.

(75) Lavie, Y.; Cao, H.; Bursten, S. L.; Giuliano, A. E.; Cabot, M. C. Accumulation of glucosylceramides in multidrug-resistant cancer cells. J. Biol. Chem. 1996, 271 (32), 19530-19536.

(76) Gutiérrez-Iglesias, G.; Hurtado, Y.; Palma-Lara, I.; López-Marure, R. Resistance to the antiproliferative effect induced by a short-chain ceramide is associated with an increase of glucosylceramide synthase, P-glycoprotein, and multidrug-resistance gene-1 in cervical cancer cells. Cancer Chemother. Pharmacol. 2014, 74 (4), 809-817. 
(77) Uchida, Y.; Murata, S.; Schmuth, M.; Behne, M. J.; Lee, J. D.; Ichikawa, S.; Elias, P. M.; Hirabayashi, Y.; Holleran, W. M. Glucosylceramide synthesis and synthase expression protect against ceramide-induced stress. J. Lipid Res. 2002, 43 (8), 1293-1302.

(78) Bowden, J. A.; Heckert, A.; Ulmer, C. Z.; Jones, C. M.; Koelmel, J. P.; Abdullah, L.; Ahonen, L.; Alnouti, Y.; Armando, A.; Asara, J. M.; et al. Harmonizing Lipidomics: NIST Interlaboratory Comparison Exercise for Lipidomics using Standard Reference Material 1950 Metabolites in Frozen Human Plasma. J. Lipid Res. 2017, in press, doi:jlr-M079012.

(79) Messner, M. C.; Cabot, M. C. Glucosylceramides in human. In Sphingolipids as sianaling and requlatory molecules; Chalfant, C., Del Poeta, M., Eds.; Advances in experimental medicine and biology; Springer Science+Business Media ; Landes Bioscience: New York, N.Y. : Austin, Tex, 2010; pp 156-164.

(80) Kavaliauskiene, S.; Skotland, T.; Sylvänne, T.; Simolin, H.; Klokk, T. I.; Torgersen, M. L.; Lingelem, A. B. D.; Simm, R.; Ekroos, K.; Sandvig, K. Novel actions of 2-deoxy-D-glucose: protection against Shiga toxins and changes in cellular lipids. Biochem. J. 2015, No. 470, 23-37.

(81) Liebisch, G.; Vizcaíno, J. A.; Köfeler, H.; Trötzmüller, M.; Griffiths, W. J.; Schmitz, G.; Spener, F.; Wakelam, M. J. Shorthand notation for lipid structures derived from mass spectrometry. J. Lipid Res. 2013, 54, 1523-1530.

(82) Garate, J.; Fernández, R.; Lage, S.; Bestard-Escalas, J.; Lopez, D. H.; Reigada, R.; Khorrami, S.; Ginard, D.; Reyes, J.; Amengual, I.; et al. Imaging mass spectrometry increased resolution using 2mercaptobenzothiazole and 2,5-diaminonaphtalene matrices: application to lipid distribution in human colon. Anal. Bioanal. Chem. 2015, 407 (16), 4697-4708.

(83) Hamilton, J. S.; Aguilar, R.; Petros, R. A.; Verbeck, G. F. DAPNe with micro-capillary separatory chemistry-coupled to MALDI-MS for the analysis of polar and non-polar lipid metabolism in one cell. J. Am. Soc. Mass Spectrom. 2017, 28 (5), 918-928.

(84) Perttu, E. K.; Kohli, A. G.; Szoka, F. C. Inverse-Phosphocholine Lipids: A Remix of a Common Phospholipid. J. Am. Chem. Soc. 2012, 134 (10), 4485-4488.

(85) Jackson, S. N.; Wang, H.-Y. J.; Woods, A. S. In situ structural characterization of phosphatidylcholines in brain tissue using MALDI-MS/MS. J. Am. Soc. Mass Spectrom. 2005, 16 (12), 2052-2056.

(86) Gaudin, M.; Panchal, M.; Auzeil, N.; Duyckaerts, C.; Brunelle, A.; Laprévote, O.; Touboul, D. Choline-containing phospholipids in microdissected human Alzheimer's disease brain senile plaque versus neuropil. Bioanalvsis 2012, 4 (17), 2153-2159.

(87) Stanley, E. G.; Jenkins, B. J.; Walker, C. G.; Koulman, A.; Browning, L.; West, A. L.; Calder, P. C.; Jebb, S. A.; Griffin, J. L. Lipidomics Profiling of Human Adipose Tissue Identifies a Pattern of Lipids Associated with Fish Oil Supplementation. J. Proteome Res. 2017, 16 (9), 3168-3179.

(88) Li, Z.; Vance, D. E. Thematic Review Series: Glycerolipids. Phosphatidylcholine and choline homeostasis. J. Lipid Res. 2008, 49 (6), 1187-1194. 


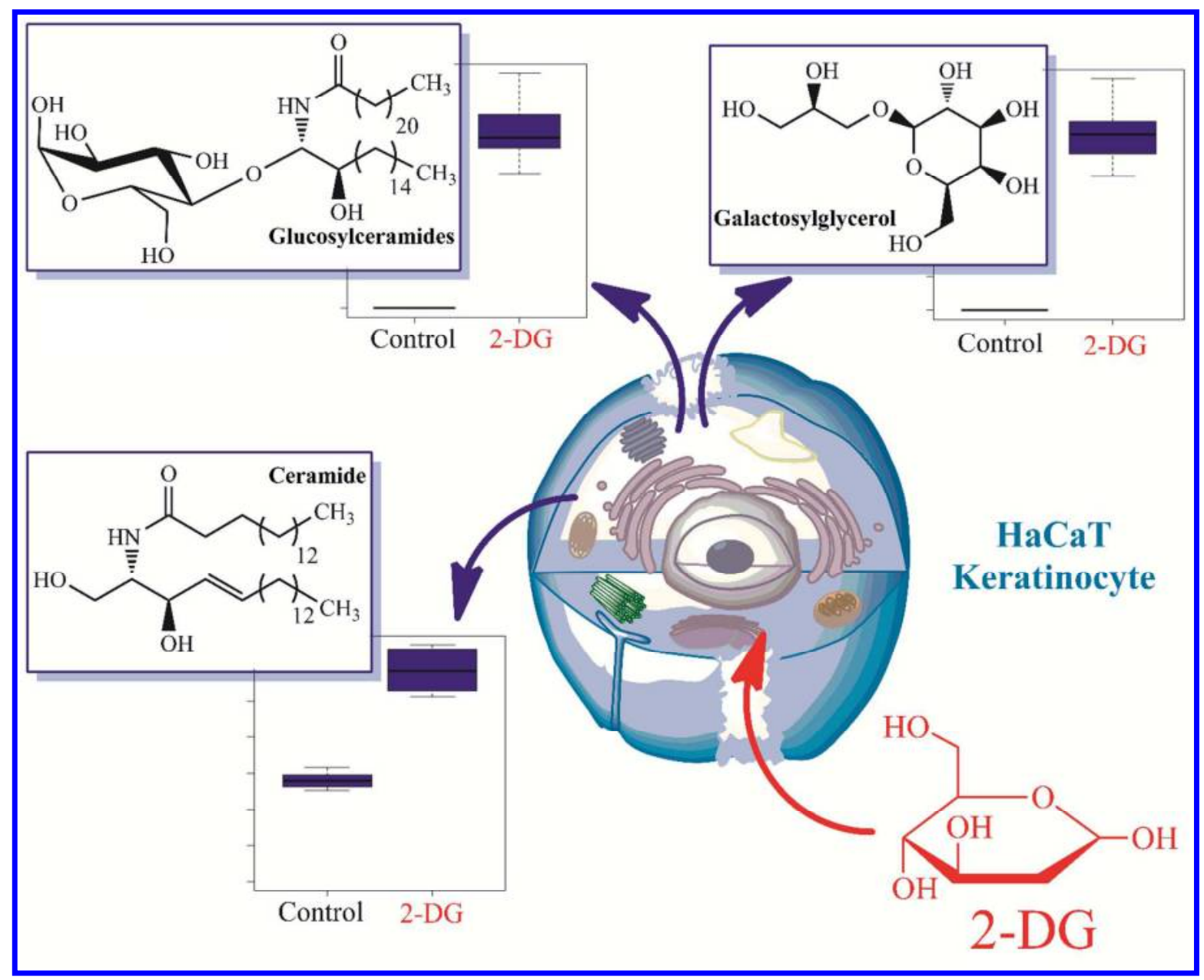


Figure 1 Schematic workflow of the analytical process for sample preparation. $355 \times 266 \mathrm{~mm}(300 \times 300 \mathrm{DPI})$ 
Figure 2 Comparison of intracellular ATP content (A) and mRNA levels of ER-resident chaperons involved in ER stress response (HSPA5/BIP and HYOU1/ORP150) $(n=3)(B)$ upon 2-DG treatment. $* P<0.01$, Welch two-sample t test.

\section{$1562 \times 1562 \mathrm{~mm}(96 \times 96 \mathrm{DPI})$}

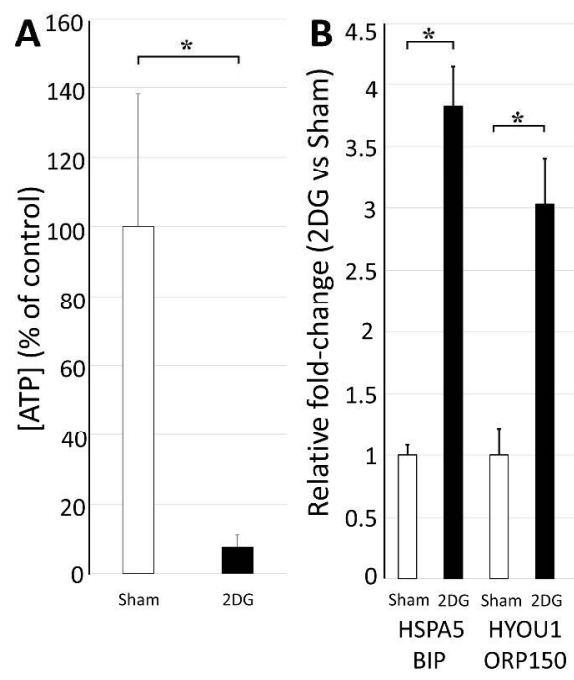




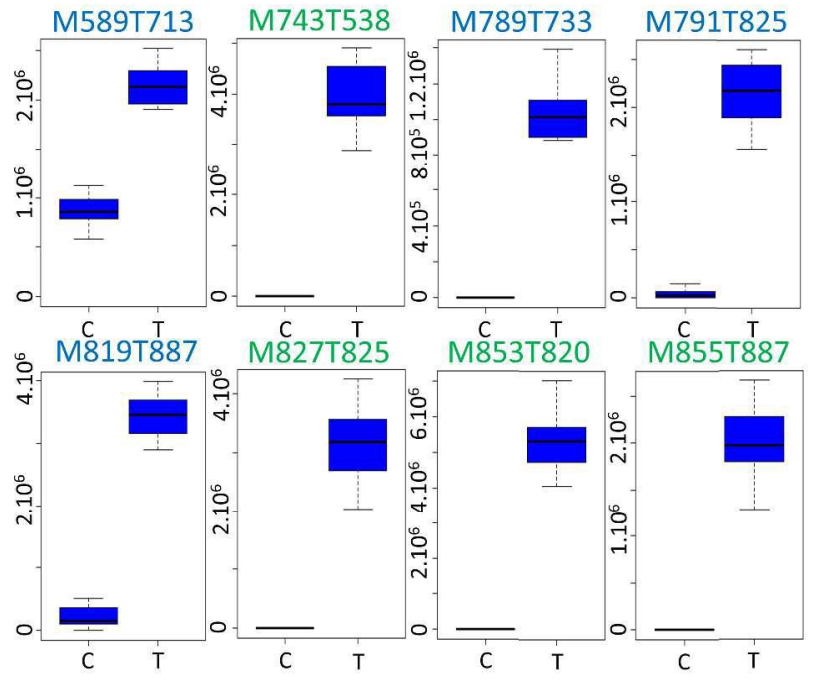

Figure 3 Box and whisker plots of the candidate biomarkers of treatment by 2-DG highlighted by lipidomic RPLC-MS analyses $(n=6)$. The y axis displays the normalized intensity of each metabolite. Features are designated as MXXXTYYY with XXX being the monoisotopic mass and YYY the retention time of the ion. Associated FC and ANOVA p-values are provided in Table 2. Features typed in blue were detected in positive-ion mode and those appearing in green arose in negative polarity.

$340 \times 536 \mathrm{~mm}(300 \times 300 \mathrm{DPI})$ 

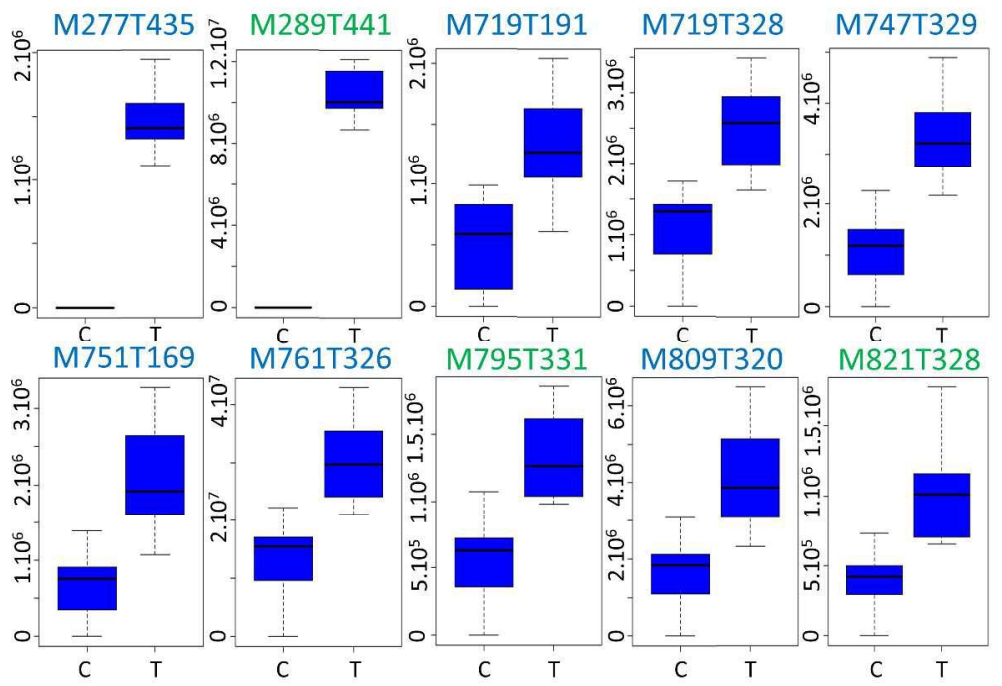

Figure 4 Box and whisker plots of the candidate biomarkers of challenge to 2-DG revealed by metabolomic HILIC analyses $(n=6)$. Features are designated as MXXXTYYY with XXX being the monoisotopic mass and YYY the retention time of the ion. Associated FC and ANOVA p-values are provided in Table 3 . Features typed in blue were detected in positive-ion mode and those appearing in green arose in negative polarity. 